\title{
LA PREHISTORIA DE LAS ISLAS CHAFARINAS A TRAVÉS DE LA ARQUEOLOGÍA
}

\author{
JUAN ANTONIO BELLVER GARRIDO \\ Director Proyecto Chafarinas \\ Instituto de Cultura Mediterránea
}

\section{EL PAISAJE PREHISTÓRICO DE LAS ISLAS}

Las islas Chafarinas han podido ser difícilmente habitadas después de los tiempos prehistóricos debido a la ausencia absoluta de agua dulce. Desconectadas de las capas freáticas que meren en la cercana costa de la egión de Quebdana, solo podían contar con la aportación hídrica que desde el cielo venía en forma de lluvia. Por eso, la historia de la vida humana en ellas tiene dos momentos bien definidos: el neolítico final a lo largo de la segunda mitad del quinto milenio antes de Cristo y la anexión española a partir de 1848. Entre ambos momentos, más de seis mil años, solo podemos adivinar visitas o establecimientos ocasionales de navegantes que consistían en un breve fondeo obligado por el mal estado del mar, pues la zona sur de las islas ofr ece protección contra los temporales . También podría aceptarse un poblamiento muy estacional vinculado a la recolección de alimentos, como los huevos de gaviotas y pardelas, o de la pesca.

Es sumamente sugerente recrear el entorno que el hombre neolítico debió observar desde las cabañas semipermanentes que hoy sabemos que construyó en la ladera de la isla del Congeso. Su mirada bajaría hacia el ulle situado a sus pies, el que com unicaba la isla del Cong reso con Isabel II. El fondo de ese v alle se encontraba a más de treinta metros ladera abajo. El peñasco que forma hoy la isla de Congreso dominaría toda la enormidad del tómbolo arenoso, el de las gigantescas dunas que ponían en contacto la costa de Cabo delAgua (Ras el Ma) hasta el extremo norte de la actual isla de Isabel II,casi cuatro kilómetros de distancia. Los restos de las megadunas aún hoy son visibles al sur de la población de Ras el Ma, únicas en la geografía del Marruecos actual. En las orillas de aquellas dunas dormitarían numerosas focas monje que pasarían el tiempo div agando entre el otro gran cabo, el de Tres Forcas y el arcaico “cabo de Chafarinas”. Descansarían 
de sus excursiones de caza y criarían sus cachorros sobre las arenas del tómbolo, sin apreciar enemigos que las amenazaran. El hombre neolítico también podría ver con claridad el otro pequeño valle que habría entre la isla de Isabel II y la del Rey, éste más modesto, de solo diez metros de profundidad, pero menos abrupto y escabroso que el primero.

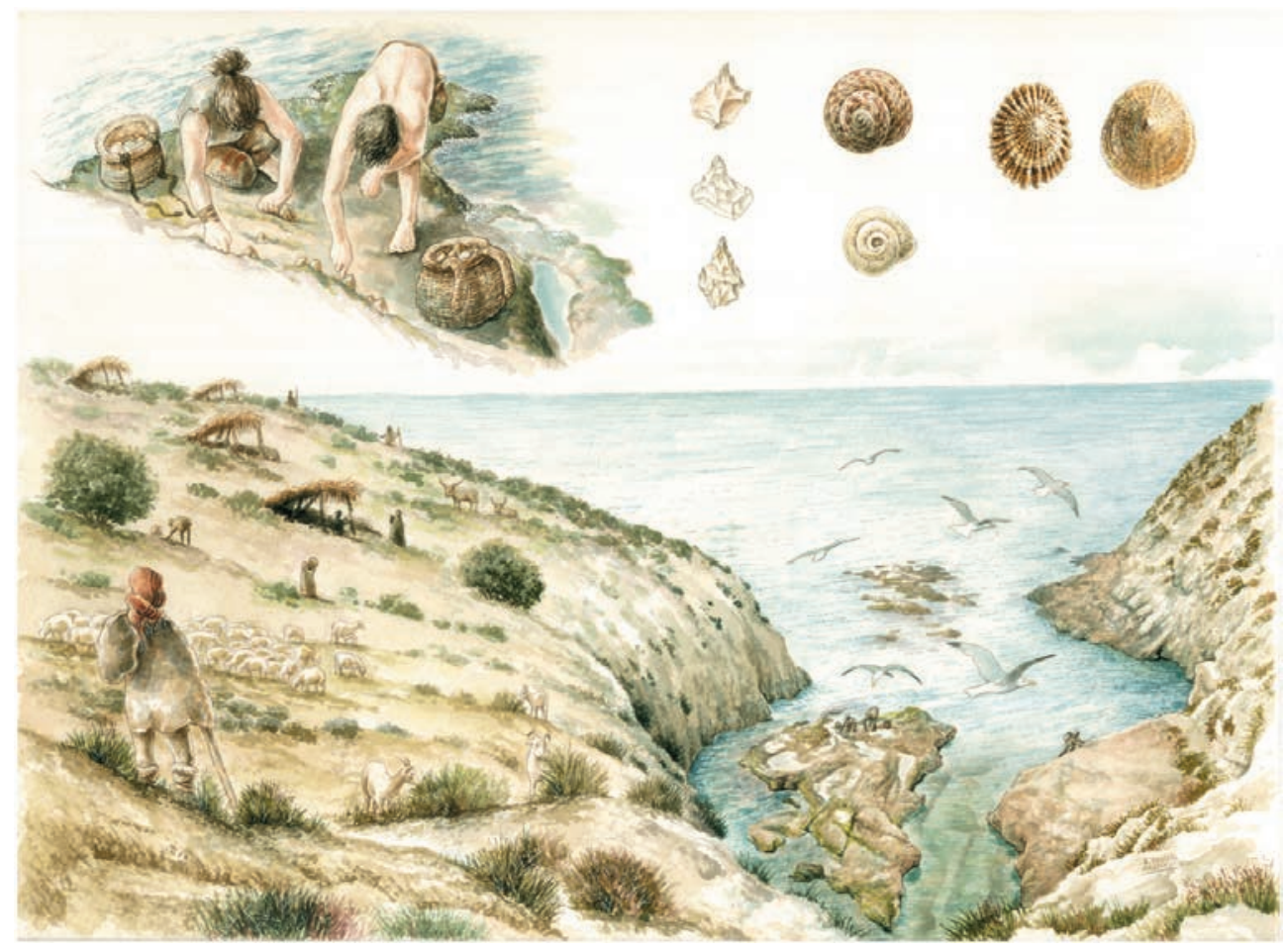

En las laderas de la isla del Congreso, durante el proceso de expansión de las comunidades neolíticas, estos pobladores establecieron un campamento estacional en torno al 4400 a. C. Dibujo: Luis Pascual (Aratikos)

Las olas batirían el morro norte de estos valles sin que apenas se pudiera percibir que poco a poco intentaban sobr epasar sus cabeceras. El paso de una generación de hombres neolíticos no sería suficiente para apreciar como la línea de costa iba r etrocediendo y el niv el del mar ele vándose, puesto que era un proceso muy lento para el tiempo humano, pero inexorable para el geológico. Estamos en los momentos del último calentamiento global, cuando el planeta eleva su temperatura media. Sin que pudieran saberlo los habitantes de Chafarinas estaban al final de un pr oceso: las superficies heladas del nor te de Europa 
seguían derritiéndose y la enor me cantidad de agua dulce que se generaba incrementaba el volumen de los océanos y con ello la subida del nivel del mar.

En mil años la costa sería distinta y el destino del cabo deendría en la transformación de un territorio continental en otro marino: El nacimiento de las islas Chafarinas. Solo el extr emo del viejo cabo, de gran altitud y con una na turaleza totalmente volcánica, de rocas magmáticas de gran dureza, va a resistir los embates de los temporales; no así el ar enoso tómbolo que se v erá disuelto y bar rido por vientos y mareas de mayor capacidad erosiva que los de tiempo atrás. Es la culminación del período inter estadial conocido como Flandriense, en plena expansión hace 10.000 años, que supuso la subida del niv el del mar por encima de la costa original. Representa el período final de la última glaciaciónłaWurm, momento en el que se terminaron de fundir buena parte de los casquetes polares que retrocedieron hasta los límites actuales. El mar entró primero en el valle más profundo: El existente entre Congreso e Isabel II, unos años más tarde penetró en el que unía Isabel II con la isla del Re y, más elevado. Finalmente todo se colapsa y la costa retrocede hasta tres kilómetros y medio al sur del actual archipiélago.

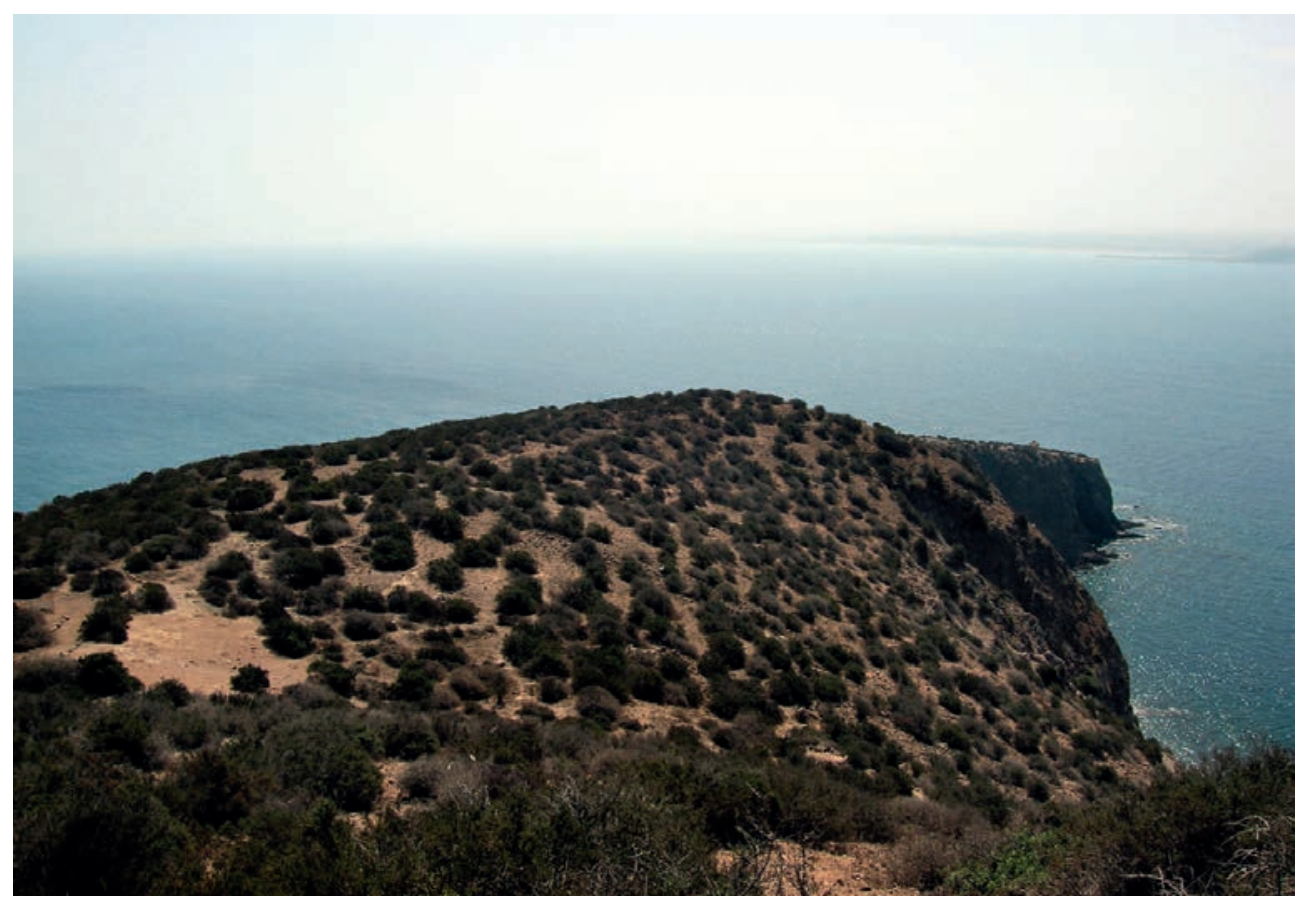

Brazo sur de la isla del Congreso frente a las costas de cabo del Agua (Marruecos). 


\section{EL ENTORNO NATURAL DE LOS ANTIGUOS POBLADORES. FLORA Y FAUNA A PARTIR DE LOS ANÁLISIS ARQUEOZOOLÓGICOS}

Conocemos el paisaje antiguo que rodeaba a ese hombre neolítico que se apoyaba en el muro delantero de su cabaña. Por el análisis de los pólenes fósiles hallados en las excavaciones sabemos que los resultados son similares a los obtenidos en el arco del mar de Alborán hace 8000 años BP (antes de ho y día): una escasa cobertura arbórea, importante masa de ma torral y maquia ter mófila, (López Saiz, J. A.; López García, P.; López Merino, L., 2010; y Expósito y Burjachs, 2003). Un ambiente xérico, con especies favorecidas por el ambiente húmedo del mar, pero especies ambientalmente cálidas. También se ha podido identificar la presencia de cereales explotados por el hombr e neolítico, lo que no es de extrañar en esta fase del período cuando en el territorio del estrecho de Gibraltar marroquí se encuentra atestiguada plenamente la agricultura en cronologías de $6350 \pm 85$ BP. Por otra parte, también habría pequeños campos de cultivo, en los que como mínimo se cultivarían cereales, con acompañamiento de centeno, cuyas semillas en esta época se mezclaban con las de tr igos, cebadas y a vena (Buxó, 1997). Como los cereales sólo aparecen documentados en las m uestras arqueológicas neolíticas, solo pueden estar relacionadas con la presencia humana en la isla, actualmente deshabitada.
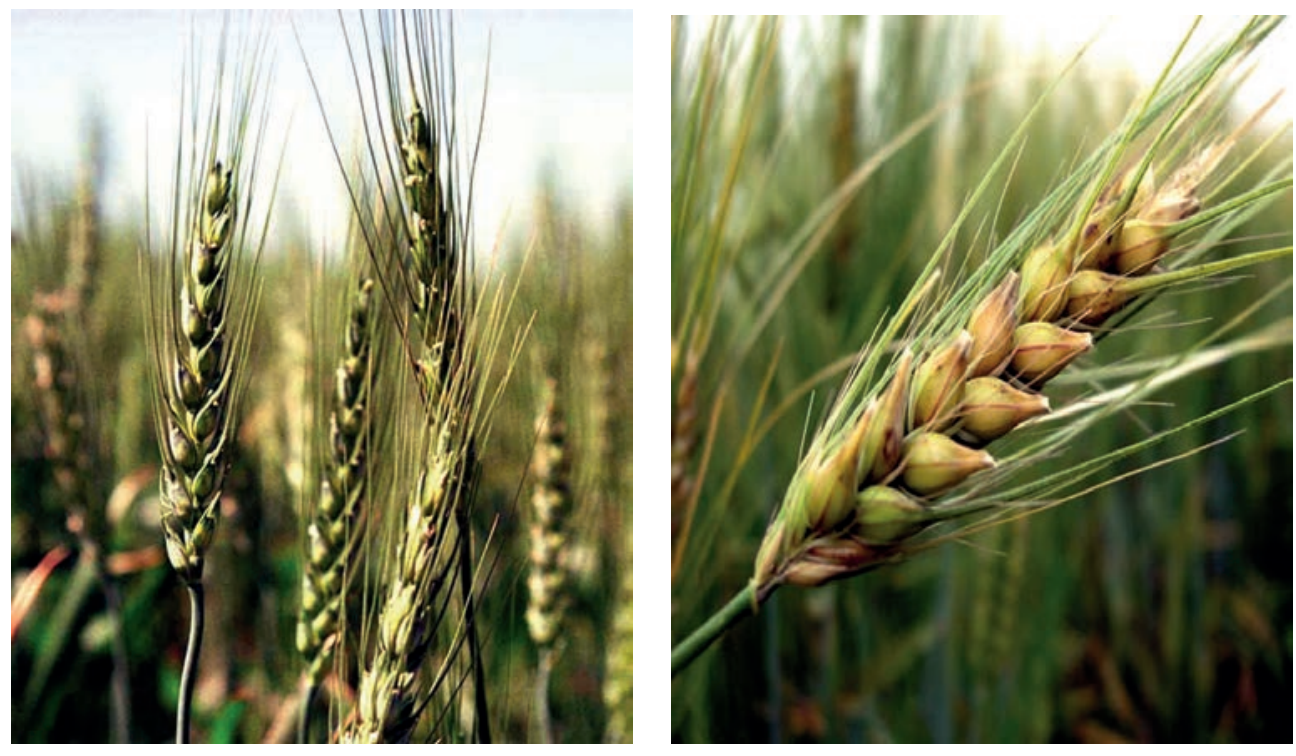

Cereales, principales plantas domesticadas en la Prehistoria: espigas de trigo, izquierda; cebada, a la derecha 
En estos campos proliferarían plantas arvenses y gramíneas silvestres. De los datos polínicos aportados por el sedimento arqueológico podemos interpretar que el entorno de Zafrín estaba constituido por un prado mediteráneo, dada la presencia mayoritaria de taxones per tenecientes a plantas herbáceas, sobre todo asteráceas, gramíneas silvestres, quenopodiáceas, llantenes, etc.

En aquella época de óptimo climático y conexión con el continente africano, la isla pudo soportar en las partes más idóneas pequeñas zonas de matorral, que estaría integrado por pinos, incipientes encinas, coscoja, efedras y jaras. Aunque al comparar el registro fósil con las muestras de control, en las del yacimiento no parecen existir grandes rasgos que nos indiquen que el paisaje del islote difería en gran medida del existente en la actualidad,sí hemos concluido que los pinos y efedras y la cobertura arbórea en general fueron más importantes en el pasado que en la actualidad.

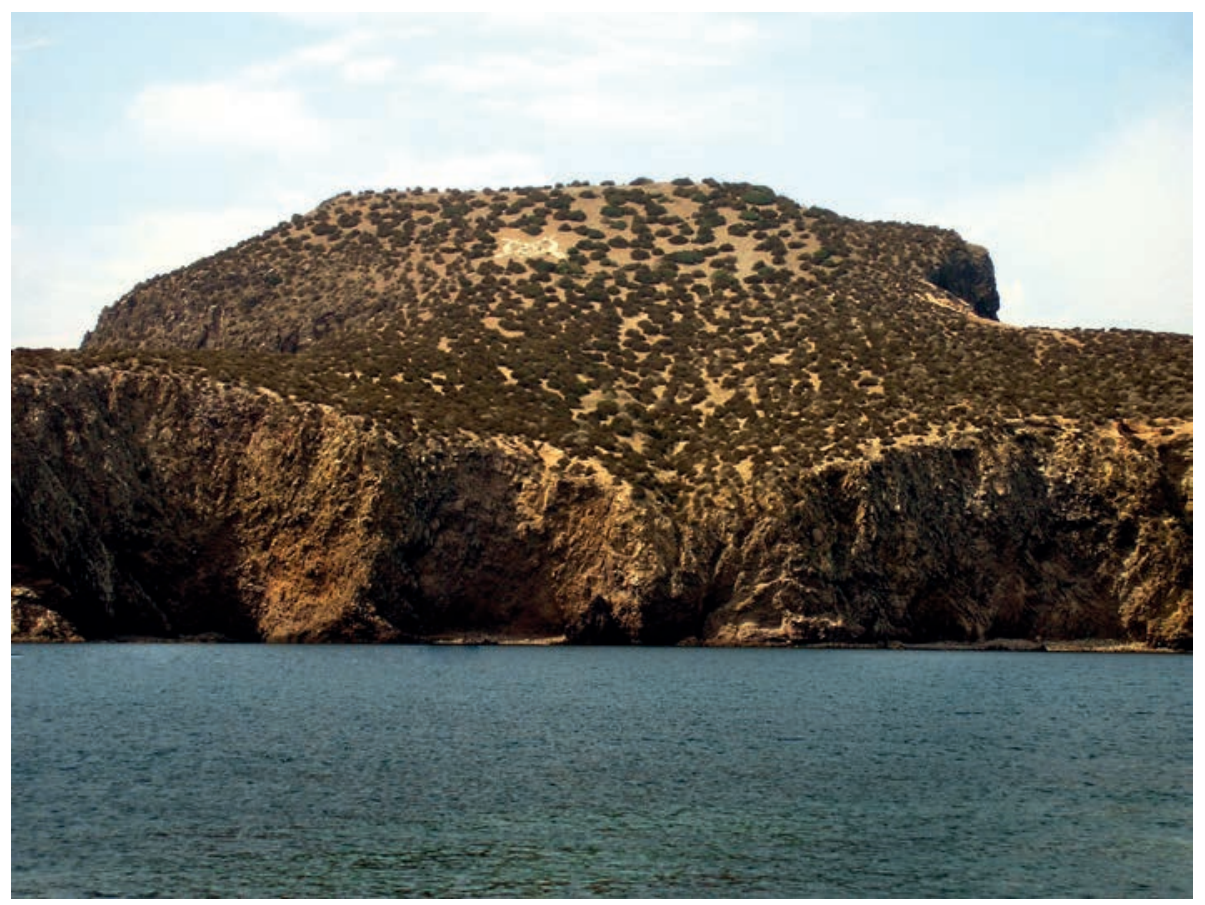

Acantilados de la isla del Congreso y superficie cubierta con vegetación herbácea y arbustiva en la actualidad.

Por otra parte, la presencia de llantenes (Plantago spp.), junto a otros taxones nitrófilos, o restos de desechos orgánicos expulsados por los animales (Asteráceas, 
etc.) y el hecho de que aparezcan en las muestras neolíticas y no en la actualidad, sería síntoma del pastoreo que se llevaba a cabo en aquellas ́́pocas. En el registro fósil, en el entorno de la cabaña y dentro de ella, encontramos huesos de animales tanto domésticos como silv estres. Las especies de mamífer os identificados son: oveja/cabra y conejo pr incipalmente. Otras faunas vinculadas a aquellos hombres fueron el perro y la foca.

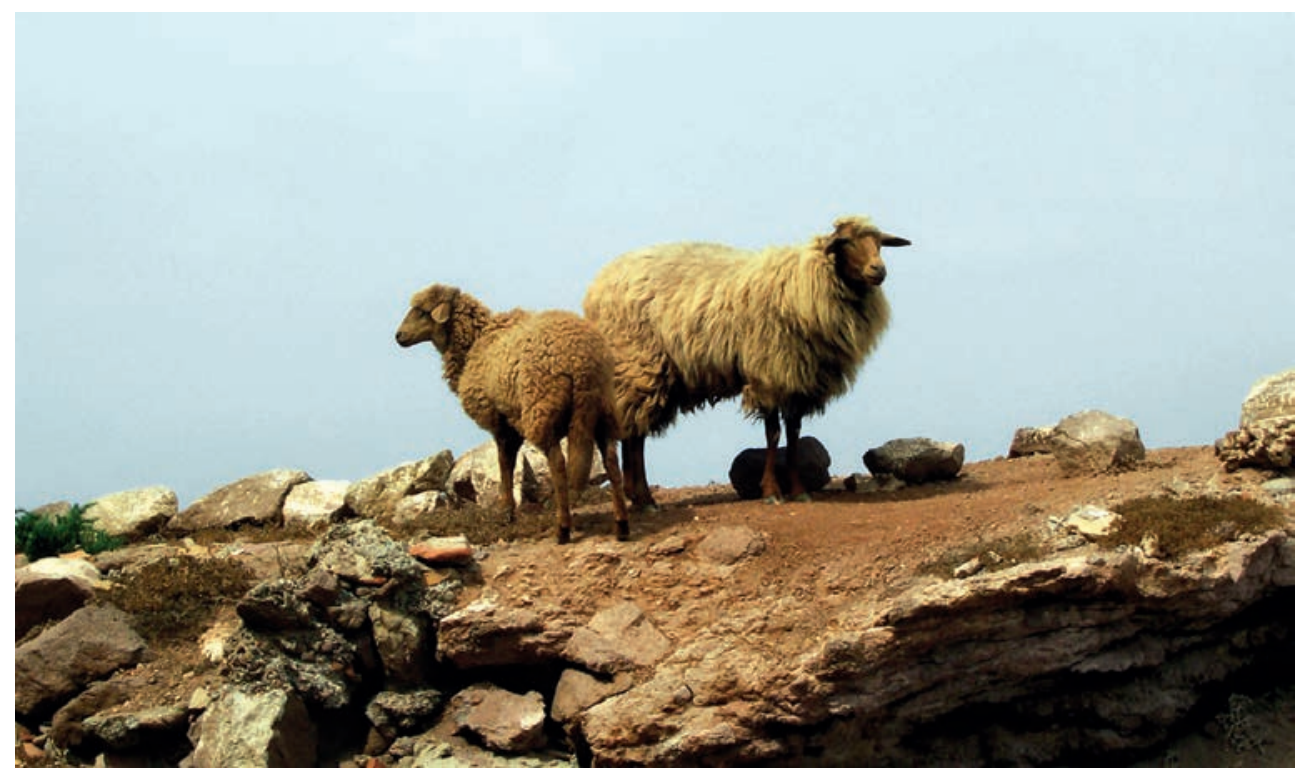

Carnero y oveja en las islas en la actualidad. Durante el Neolítico la domesticación de algunas especies, como por ejemplo el ganado ovicaprino o el vacuno, tuvo como consecuencia importantes transformaciones en la anatomía de los animales.

Nuestro hombre, vigilaba sentado apaciblemente la pequeña punta de ovejas y cabras. Más de una docena de animales han sido r econocidos en el análisis arqueozoológico, era un rebaño con animales en distintas fases de crecimiento, al menos dos contaban con menos de doce meses de edad, subadultos, según parece indicar las mandíbulas y, por una falange, supimos de la presencia de otro animal de menos de seis meses. Hay también un individuo de mayor tamaño que podría ser un adulto macho o un arruí silvestre.

Muy numerosos han sido los restos de foca. Parece que los animales eran en su mayoría ejemplares muy jóvenes, cachorros cazados por el hombr e casi con toda seguridad sobre las arenas de las playas. De igual modo, identificamos 
grandes colmillos procedentes de focas ya adultas, sin que podamos asegurar su caza, si bien, sí su aprovechamiento: extremidades y cráneos aplastados son ejemplos de su consumo pero nos dan poca información.
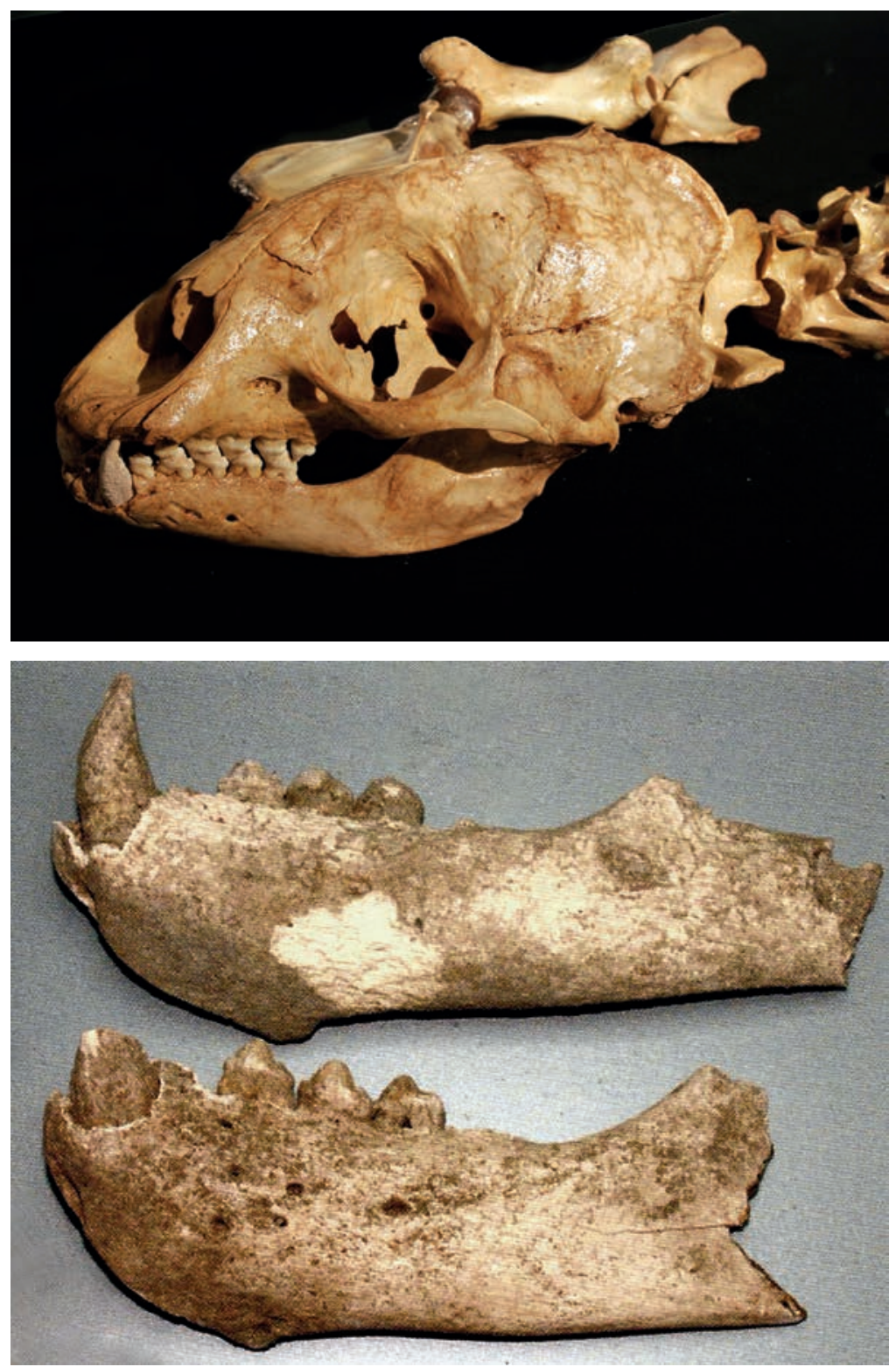

En la imagen de arriba un ejemplar actual de foca monje (Monachus monachus). Abajo mandíbulas de la misma especie excavadas en el yacimiento de Zafrín. 
El hombre neolítico de Chafar inas ya estaba acompañado por el más viejo amigo con que ha contado el ser humano en el m undo animal: el perro, seguramente mientras manipulaba unos caracoles terrestres, hélix, en una gran olla cerámica, le acompañaba vigilante. Éstos controlaban los rebaños y avisaban de posibles peligros. Hemos podido estudiar los pocos restos de dos animales, de edad avanzada, que hemos recuperado en los paleosuelos del entorno de la cabaña.

Constatamos la manipulación de los huesos para extracción medular específicamente en el caso de los ovicaprinos. Para ello se eligen los huesos largos: húmero, fémur, radio, etc., una vez vaciados de su médula, una fuente de alimento muy nutritivo, se convierten en materia prima para confeccionar útiles: espátulas, puntas, etc., todo para labor es como decorar las cerámicas, la manipulación de tejidos y cuer os, etc. Esta actividad, junto con el pisoteado , atomiza los taxones y hace difícil la identificación de los huesos y por tanto la de las especies. Perdemos datos como la edad, sexo, talla, etc., de los animales y por tanto pautas de explotación de las cabañas ganaderas. Todas las manipulaciones dejan huella en los huesos. El descarnamiento para separar la car ne del hueso deja cortes pequeños, cortos, pero suficientemente profundos para ser estudiados y nos permiten identificar los patrones de despiece de los animales.

En el neolítico de la zona no tenemos aún constancia de la capacidad del hombre para navegar, sin embargo el mar era fuente impor tante de alimentos. Las rocas alojaban las numerosas especies de lapas, se han identificado cinco tipos distintas, entre los que destacan las fer rugíneas y las safianas. Además de estos gasterópodos, también se recolectaban bivalvos como los mejillones. Igualmente se han identificado percebes, de mayor tamaño que los actuales (ÁlvarezFernández, E., 2010). Las islas aún conser van, de una for ma u otra, casi todas estas especies, tanto en número como en morfología. Las rocas semisumergidas y las más cercanas a la costa servían de protección a las especies de pescado que llamamos de roca, serránidos (meros, falsos abadejos, etc.) y espáridos (doradas, pargos, etc.) puesto que son numerosísimas las vértebras de estos peces que se han recogido en el yacimiento.

Caso especial es el del apr ovechamiento de la foca monje ( Monachus monachus). Un animal que ofrece unas amplias posibilidades de explotación, de gran capacidad para alimentar a un grupo humano: carne, grasa, tendones, huesos, todo ello en abundancia. Su caza se desarrollaría en las playas y plataformas rocosas del cabo. En tier ra el animal no tiene posibilidades para defender se (Bellver, J., 2010). 


\section{ÚTILESY UTENSILIOS DEL HOMBRE NEOLÍTICO DE ZAFRÍN}

El hábitat circundante proporcionaba al hombre las materias primas que necesitaba para transformarlas en útiles y herramientas. La materia prima más cercana estaría en las grietas formadas entre las rocas volcánicas, en la pared norte de la isla del Rey, allí era donde aparecían unas finas betas de una piedra muy rojiza que delataba su elevado contenido en hierro. Es el sílex, el pedernal, la materia prima universal que el hombr e manipulaba para constr uir sus her ramientas de cor te: puntas de lanza, cuchillitos, todo para cor tar y preparar sus alimentos. Hoy aún pueden verse en este lugar la cantera donde afnosamente se recolectaban en bruto los núcleos de los que, más tarde, se extraerían las lascas. 'Éstas, una vez manipuladas, se tallaban para transformarlas finalmente en los útiles de cortar.
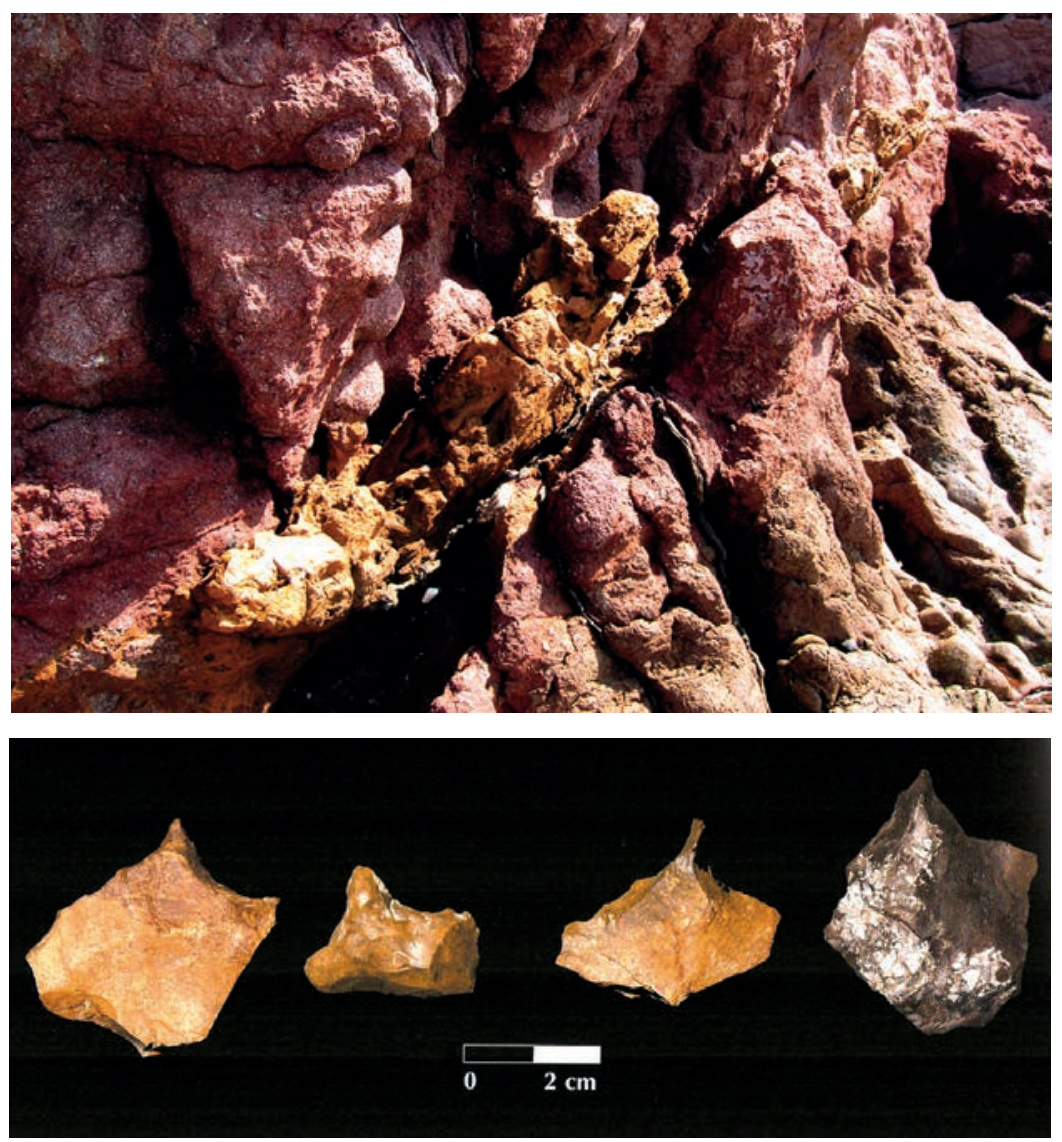

Vetas de sílex en la isla de Isabel II. Abajo perforadores del mismo material extraídos del yacimiento de Zafrín. 
Sin embargo, del análisis de los distintos sílex hallados en exca vación, sabemos que junto a la utilización del sílex en la isla del Re y también hubo una recogida de esta materia prima en distintas áreas cercanas, como lo fueron seguramente en los lec hos de los ríos próximos. Los ar rastres fluviales dan como resultado la aglomeración de ma terias primas de diverso origen que terminan depositando en las zonas bajas de sus desembocaduras. Del análisis traceológico de los sílex (Gibaja Gao, F., 2010) se concluye la existencia de huellas de uso en los útiles; esto confirma que con ellos se ha pr ocesado carne y se han tra tado pieles principalmente. También en los análisis se han identificado huellas de trabajo sobre madera o hueso.

La riqueza cerámica es muy destacable en Chafarinas. La cerámica es un invento neolítico y por tanto una de sus características or iginales. Sus formas y decoraciones se convertirán en el sello de identidad de cada época e incluso de cada pueblo de la Prehistoria y la Antigüedad. En este caso existe una gan muestra de ella tanto cuantita tiva como cualitativamente. Las distintas campañas de excavación y prospección arqueológica llevadas a cabo en el asentamiento de Zafrín han permitido recuperar varios miles de fragmentos de cerámica. Su elaboración fue tosca y tenían como finalidad el uso culinario, para preparación de comida, bebida y por supuesto de almacenaje . De forma minoritaria también contamos con muestras de cerámica fina ya en su modelado, su acabado y con una interesante ornamentación muy elaborada. Por los análisis realizados sabemos que las arcillas utilizadas para su fbricación fueron locales. El tipo de decoración es el específico del neolítico llamado cardial, con las pasta de la cerámica aún sin cocer se hacían las incisiones e impresiones sobre su superficie. Siempre repitiendo los esquemas decorativos de modo que los signos y formas resultantes son la marca reconocible de culturas geográficamente identificables: "espina de pescado", "zig-zag", aterciopelados, etc. 

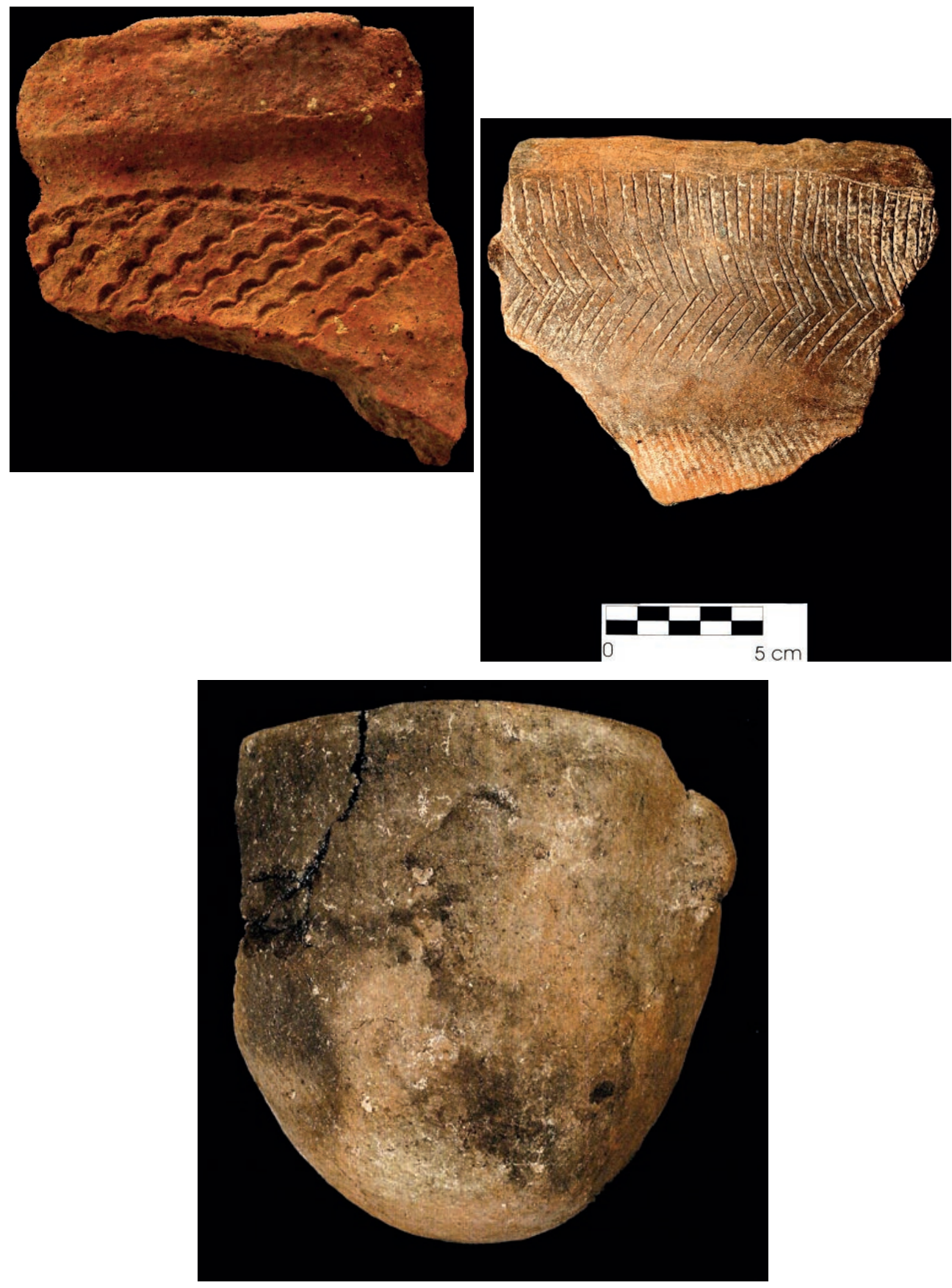

De arriba a abajo. Borde cerámico con decoración cardial en el exterior; Cuenco cerámico con decoración cardial y aterciopelada (tipo veloute) externa; Olla cerámica lisa con mamelón vertical perforado a la derecha, todas extraídas del yacimiento de Zafrín. 
El Cardium, es el nombre científico de la vulgar concha que nos encontramos al pasear por nuestras playas mediterráneas. Se trata del útil activo que se ha usado tradicionalmente para decorar estas cerámicas que constituyen el utensilio básico del llamado neolítico Cardial que se extendió por gan parte del Mediterráneo. Sin embargo, la aplicación de la arqueología experimental en nuestros trabajos de laboratorio confirmó que las decoraciones cerámicas en el pob lado de Zafrín estaban elaboradas con la conda de la Patella ferruginea, muy abundante en la zona, y no con Cardium. Pero el tipo de concha utilizada en la decoración de las cerámicas es en $r$ ealidad algo poco r elevante y por este motiv o estas gentes son definidos como hombres del "Neolítico Cardial”, independientemente del tipo de condhas utilizadas como instrumento para decorar. Como complemento para almacenar, especialmente agua, el hombre neolítico cuenta además con los huevos de avestruz que utilizará a modo de cantimploras Más resistentes que la propia cerámica, son transportados dentro de un cesto de cañas en sus desplazamientos de caza y recolección.

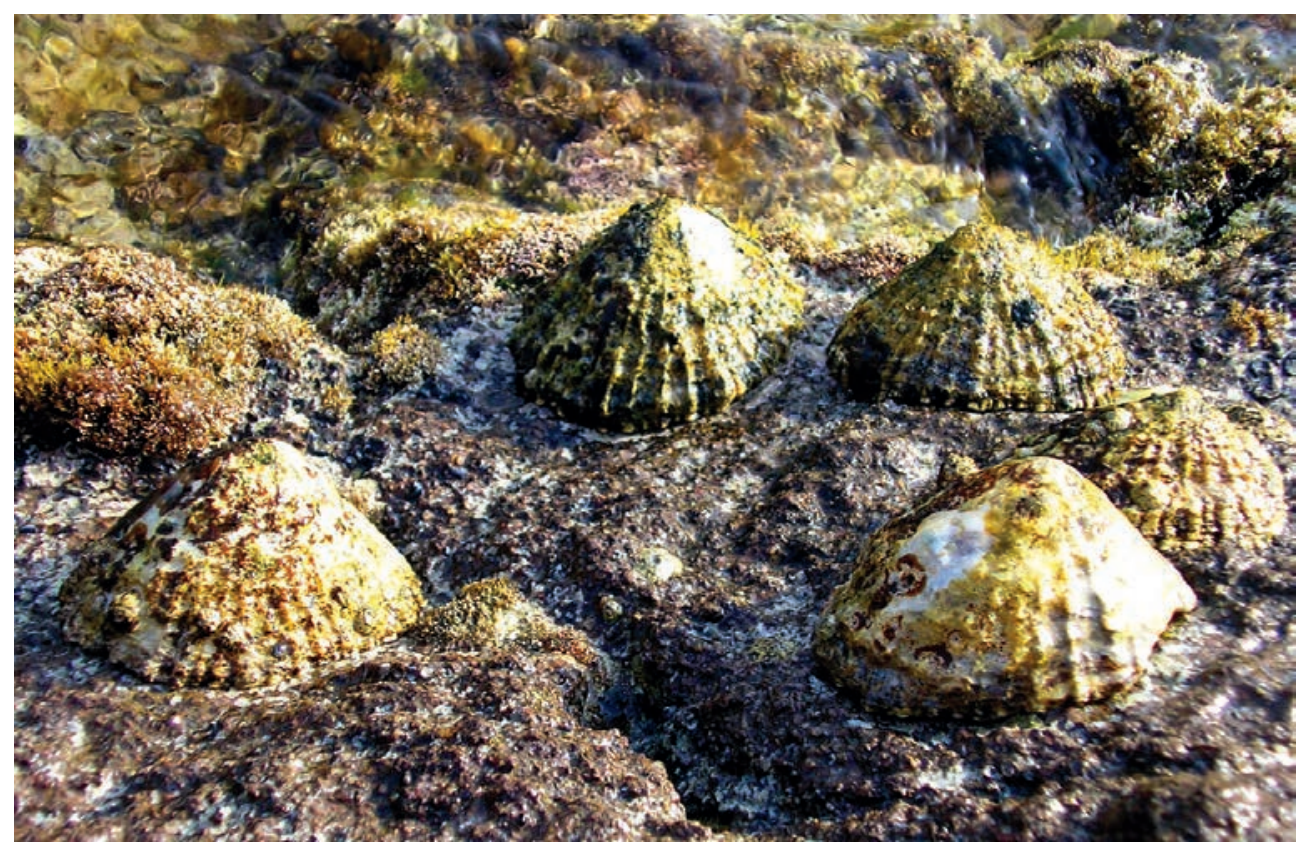

Ejemplares de Patella ferruginea aferradas a la roca actualmente en las islas. 

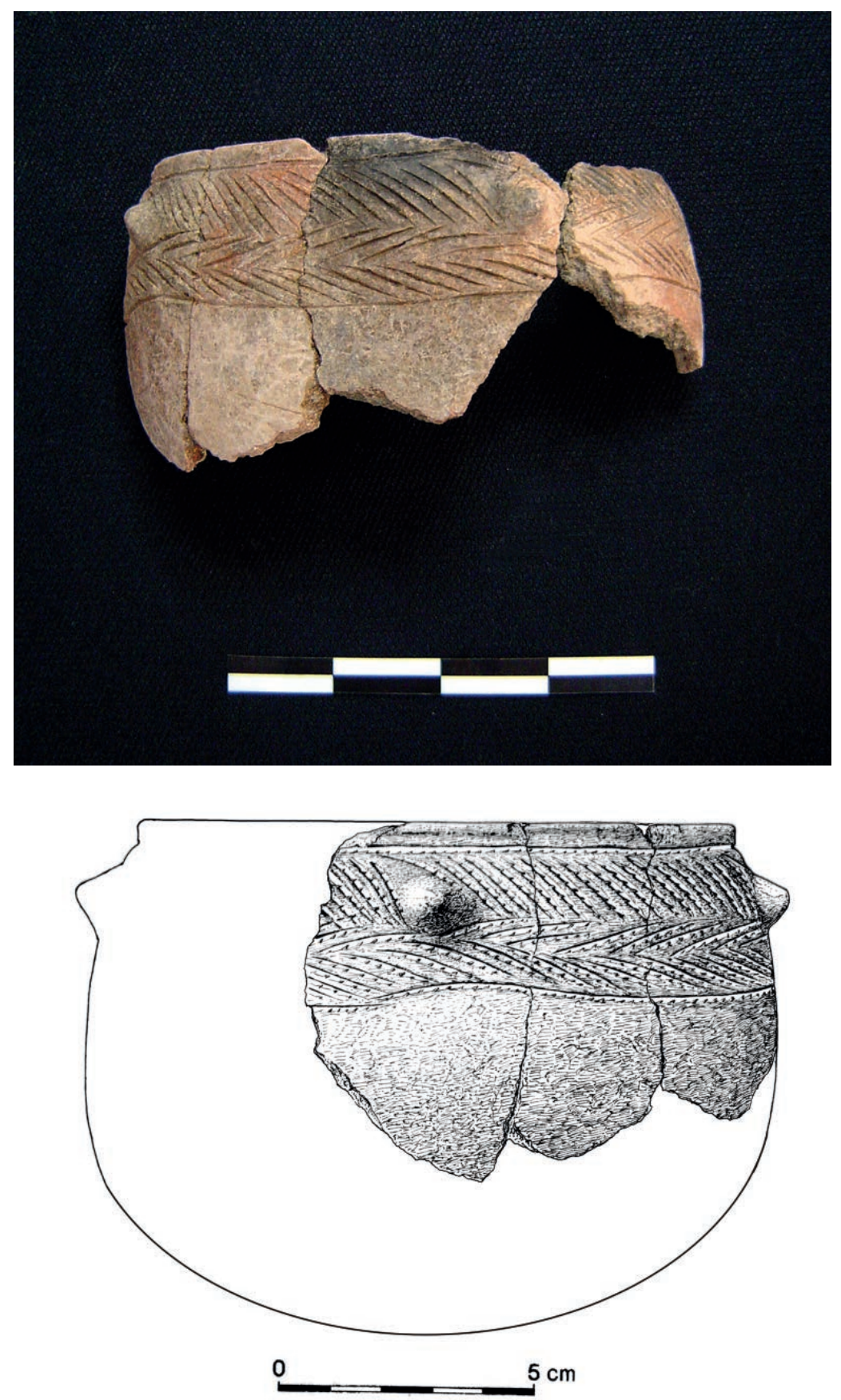

Pequeña olla con cuidada decoración cardial en el exterior y reducidos mamelones alrededor del borde del yacimiento de Zafrín. Dibujo de Ángel Rodríguez. 


\section{EL ORIGEN DE LA ARQUEOLOGÍA EN LAS ISLAS CHAFARINAS. DESCUBRIMIENTO DEL POBLADO NEOLÍTICO DE ZAFRÍN EN LA I CAMP AÑA DE EXCAVACIÓN ARQUEOLÓGICA}

Toda esta información que podemos detallar actualmente fue viendo la luz durante el proceso de investigación que el Instituto de Cultura Mediter ránea comenzó en el año 2000, cuando se inicia un proyecto de prospección e investigación en el territorio melillense. El proyecto se inició con un trabajo previo de búsqueda bibliográfica sobre la prehistoria en Melilla e islas Chafarinas. La referencia a la existencia de un jacimiento en el archipiélago, deducida de un trabajo del profesor Carlos Posac Mon, (Posac, 1956) moverá al Instituto a iniciar una investigación que dará como resultado la I Campaña de intervención arqueológica en las islas Chafarinas.

Las prospecciones realizadas entre el año 2000 y 2001,previas a la intervención, permitieron recuperar piezas de excepcional impor tancia que confirmaron sin lugar a dudas la existencia del yacimiento. Muchos de los elementos cerámicos recuperados estaban profusamente decorados y tipológicamente atendían a la cerámica cardial de época neolítica.En estas prospecciones se estimó la superficie del yacimiento en 1.200 metros cuadrados aproximadamente, y se recogieron numerosos restos de cerámica e industria lítica. Estas fructíferas prospecciones auguraban que las futuras intervenciones serían de un interés fuera de lo común.

En la fase siguiente, ya en el verano de 2001, se inician las excavaciones de la I Campaña. Se realizó un sondeo en el brazo sur de la isla del Congeso, dentro de la superficie estimada como y acimiento. El área de 16 metr os cuadrados se dividió en cuatro cuadrículas de $2 \times 2 \mathrm{~m}^{2}$. En el momento de eleg ir la zona de excavación, se tuvier on en cuenta las $\mathrm{r}$ ecomendaciones de los especialistas medioambientales de Parques Nacionales, para no afectar a ninguna de las especies vegetales protegidas y causar el menor impacto posib le en la v egetación. Con el fin de llegar a los niveles de calidad medio ambiental necesarios a partir del año 2003, se llevará a cabo un estudio previo de impacto ambiental encargado por la Fundación Biodiv ersidad, dependiente del Minister io de Medio Ambiente. En él se planificó toda la actuación previa a la remoción de tierra provocada por la excavación arqueológica. Posteriormente, una vez finalizada la campaña, se procedía a la repoblación de la zona removida con el trasplante de bulbos de las especies afectadas y con calificación de potección, según contemplaba 
el catálogo de especies singulares del Organismo Autónomo de Parques Nacionales y siempre en consonancia con las conclusiones del estudio de impacto.

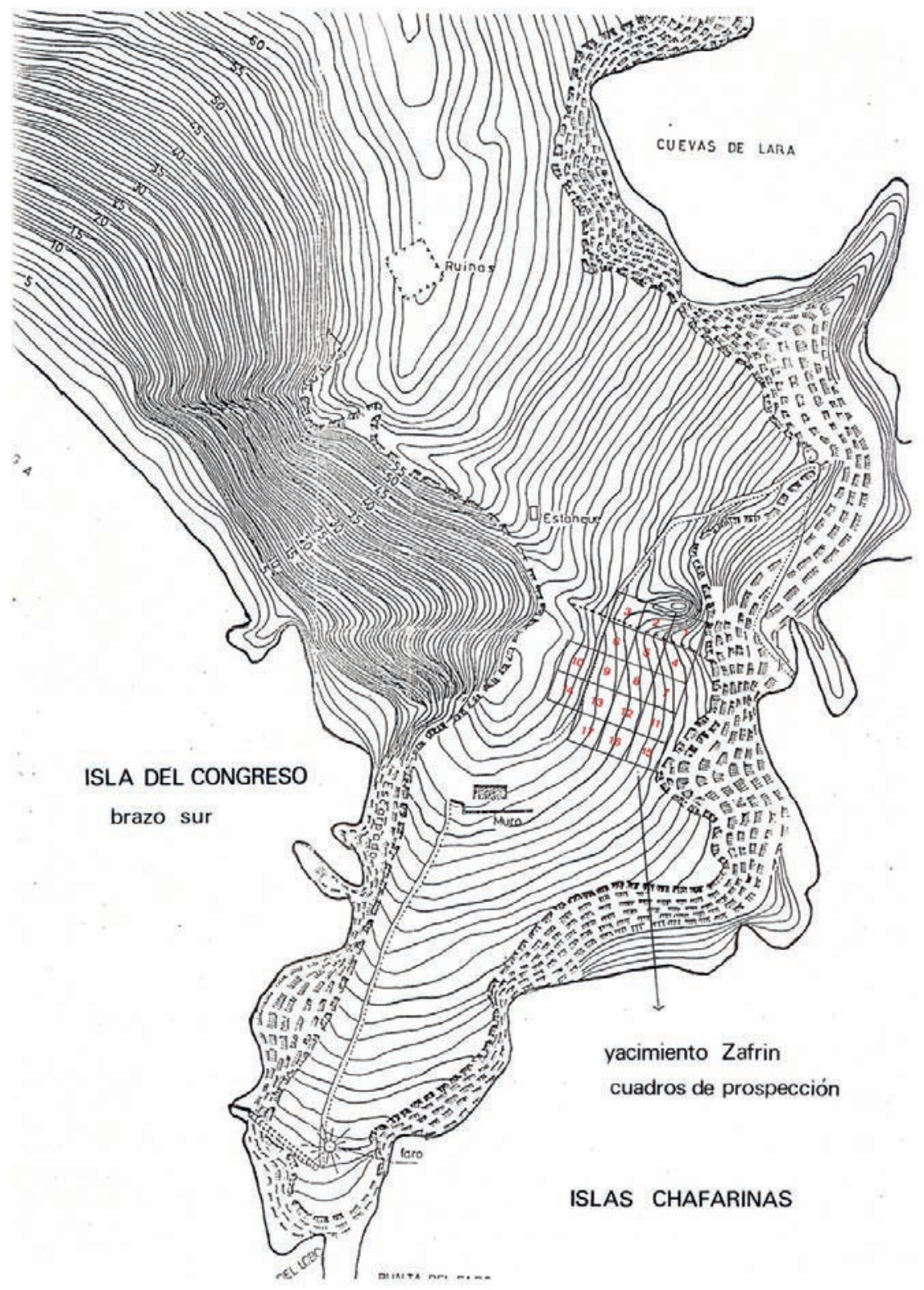

Brazo sur de la isla del Congreso. Zona delimitada como yacimiento a partir de las prospecciones realizadas en el año 2000. 


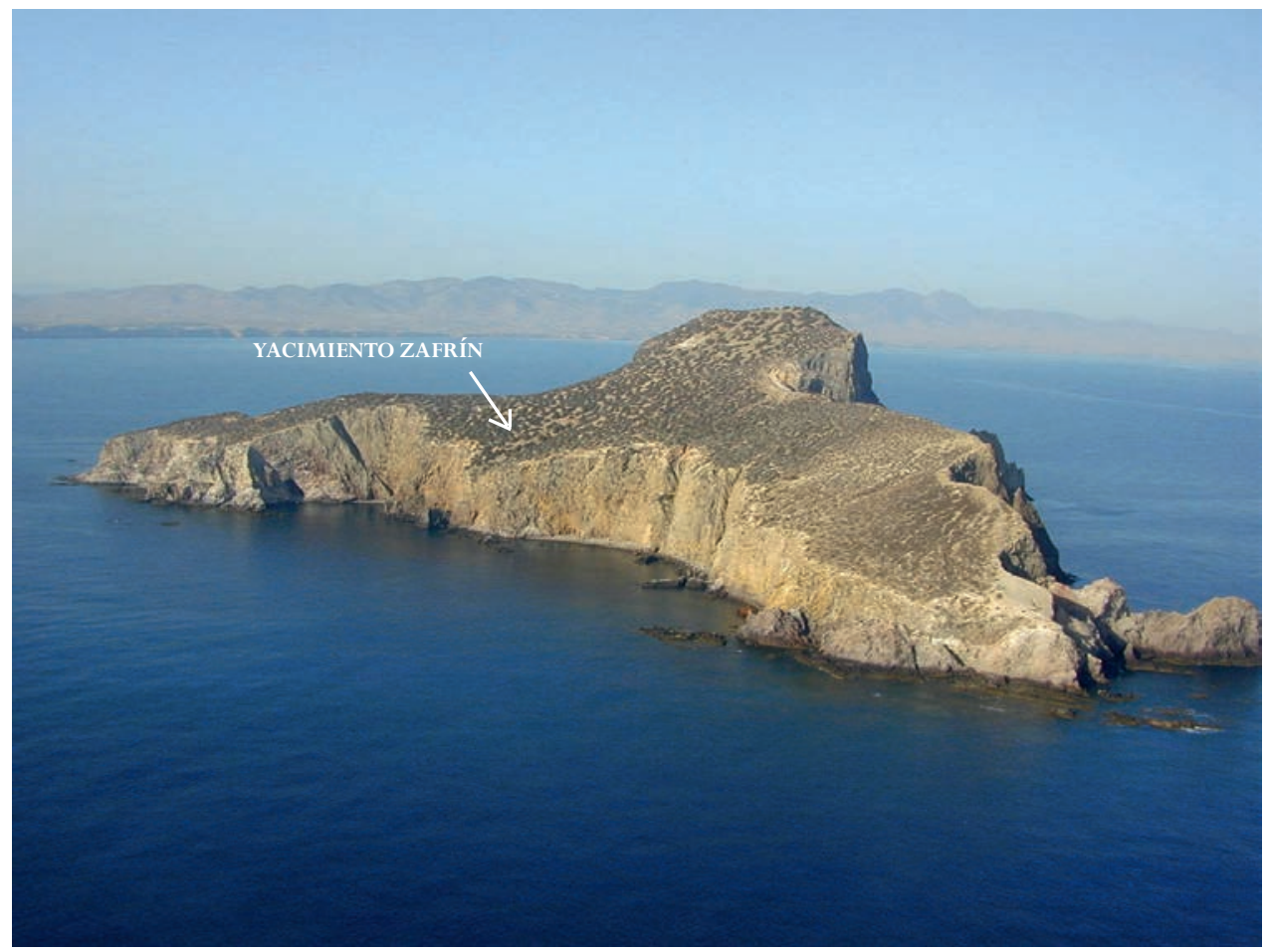

El yacimiento de Zafrín se encuentra situado en el brazo sur de la isla del Congreso sobre una superficie fuertemente inclinada que bascula hacia el este.

Junto a la citada cuadrícula de $16 \mathrm{~m}^{2}$, sector principal de esta pr imera intervención, se realizó un sondeo más hacia el Este y a una distancia apoximada de 5 metros.

En la cuadrícula principal, se hallaron en superficie numerosos caracoles terrestres y algunas conchas de lapas mezclados con fragmentos de cerámica.La matriz era arenosa-arcillosa de color grisácea con piedras calizas y andesitas . A este nivel superficial le sucedía un paleosuelo de arcillas $r$ ojizas apisonadas sin cantillos ni piedras. Igualmente en los cuadros 1, 3 y 4 se identificaron tres hogares, dos de ellos muy prolíficos en cuanto a materiales. En el cuadro 2 junto al hogar, apareció una estructura negativa, una cubeta de unos 75 centímetros de profundidad y de planta rectangular. Dentro de ella se vació una enorme caracolada y restos de una cerámica de g ran tamaño que se or ientaba verticalmente en el sedimento. En el fondo varias piedras de tamaño medio anunciaban el nirel estéril de la roca madre. La matriz era grisácea como la del nivel superficial, acom- 
pañada de numerosos caracoles terrestres (hélix). A todo lo descrito lo denominamos Nivel II. En la confluencia de las cuadrículas 3 y 4 se obser vó que el yacimiento estaba arrasado por la erosión, mostrando un área de piedras calizas en descomposición en matriz arcillosa rojiza sin material arqueológico. Sólo por debajo del hogar del cuadro 3 se percibía un nuevo nivel de caracoles con matriz arcillosa-arenosa de color grisácea, sin embargo, la falta de tiempo obligó a dejar inconclusa esta zona. El hecho de que esto ocur riera en menos de un metr o cuadrado y estando el hogar casi clarado en el cantil suroeste del sondeo aconsejó dejarlo para ser excavado en la siguiente campaña.

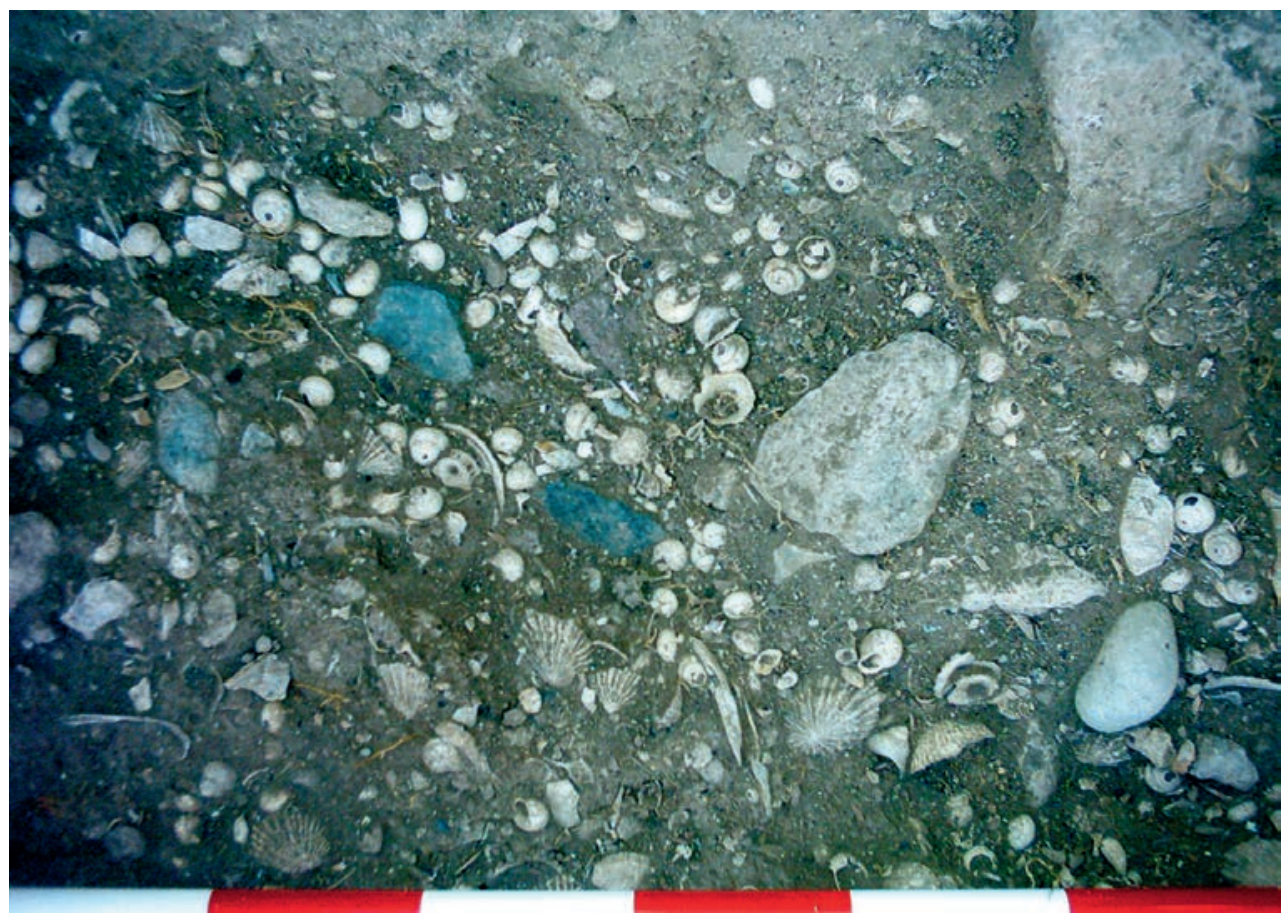

Matriz arenosa-arcillosa de color grisácea con abundante acumulación de conchas (lapas, caracoles terrestres, mejillones, etc.) durante la campaña de 2001.

En cuanto al segundo sondeo, se trató de una excavación de control. Pudimos ver, tras limpiar el matorral que cubría la superficie de excavación propiamente dicha, que podía vislumbrase un alineamiento de piedras posibemente de un muro. Se abrió un metro cuadrado escaso y se identificar on cinco niveles. 
Primera nivelación formada por bloques y piedras de tamaño medio un segundo nivel compuesto de arcillas con g ran cantidad de material orgánico y restos de caracoles, un tercer niv el de tier ra rojiza arenosa, un cuar to formado por la descomposición de la roca madre y un quinto la roca madre propiamente dicha. En los cuatro primeros se recogieron materiales arqueológicos como cerámica cardial, lisa, espatulada, y sílex. Finalmente se cubrió la zona sin confirmarse la existencia del muro.

Esta primera intervención arqueológica permitió documentar en las islas la existencia de su ocupación por gentes neolíticas. No solo del paso esporádico de éstos sino la ocupación permanente de ellas. En concreto, un nivel identificado como un paleosuelo formado por un apisonado de arcilla y aena con ausencia de cantillos, en el que se encontraron tres áreas de combustión, fueron las primeras muestras de presencia más o menos permanente. Los materiales fragmentados y pisoteados in situ permitieron confirmar los restos, en casos aún intactos, de la superficie de actividad primitiva. De la excavación surgió una distribución espacial de áreas de vivienda que no nos permitió reconocer la planta de la misma. Sí sabemos, por campañas posteriores, que estábamos ante una cabaña,pero no pudimos determinar si esta era circular, rectangular o si por el contrario era una estructura abierta. Como comentamos más ar riba, también se halló una interfase inversa o cubeta de un metro cúbico relleno de basura como conchas, caracoles, huesos y cerámica. Todo ello permitió determinar el tipo de hábita t ante el que nos encontramos y sus posib les distribuciones espaciales: áreas de taller, de desollado de animales, de descanso, etc., pero no hoyos de poste que indicaran la presencia de una estructura.

La cuadrícula original fue ampliándose en campañas posteriores, trabajos sobre el sector con mayor densidad de ocupación que aportaron nuevos datos e importantes hallazgos que caracterizaron el yacimiento de Zafrín.En el año 2003 (el incidente de la isla P erejil impidió realizar la campaña en el año 2002) se desarrolló la segunda campaña de excavación, en este momento se volvió a abrir un cuadro de 2 x 2 m.inconcluso de la campaña de 2001 y tres cuadros más de 2 x $2 \mathrm{~m}$., lo que for maría una nue va cuadrícula de 4 x 4 metr os. Durante esta intervención se documentaron inter esantes estructuras de hábitat tales como hogares o cubetas, a las que se le añadió impor tantes hallazgos de material arqueológico, cerámicos y óseos. 


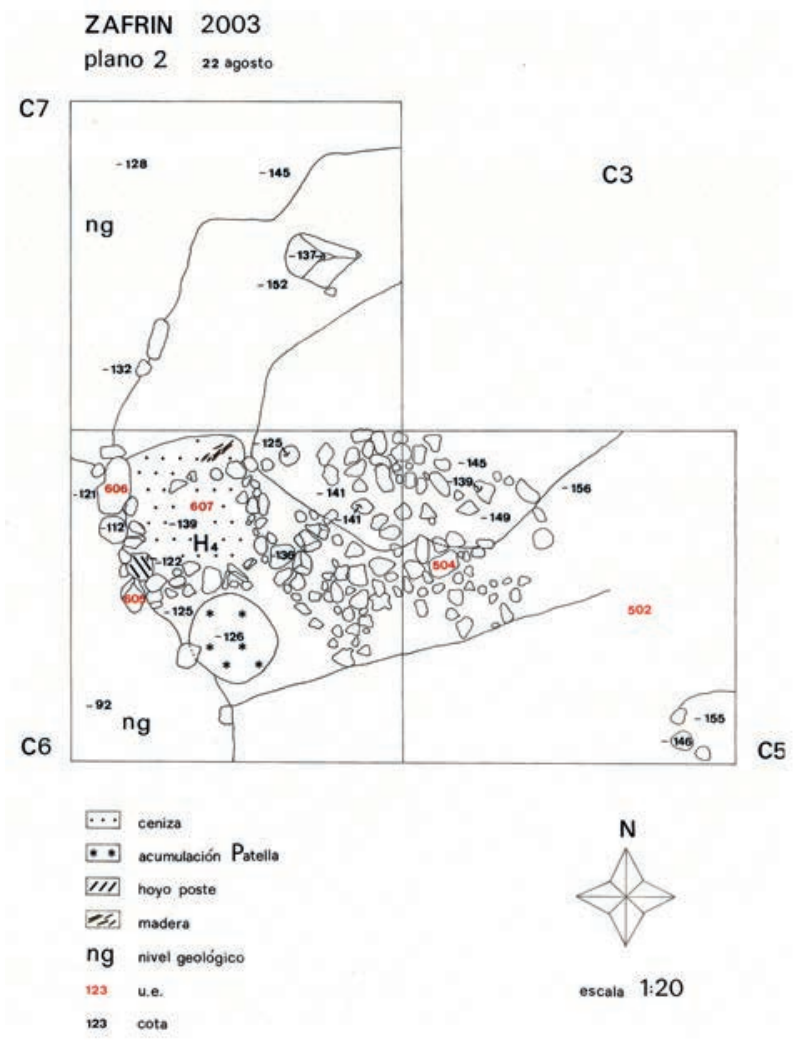

Plano de la campaña de 2003 donde se indican algunas estructuras (hoyos), zonas de combustión y la característica acumulación de conchas.

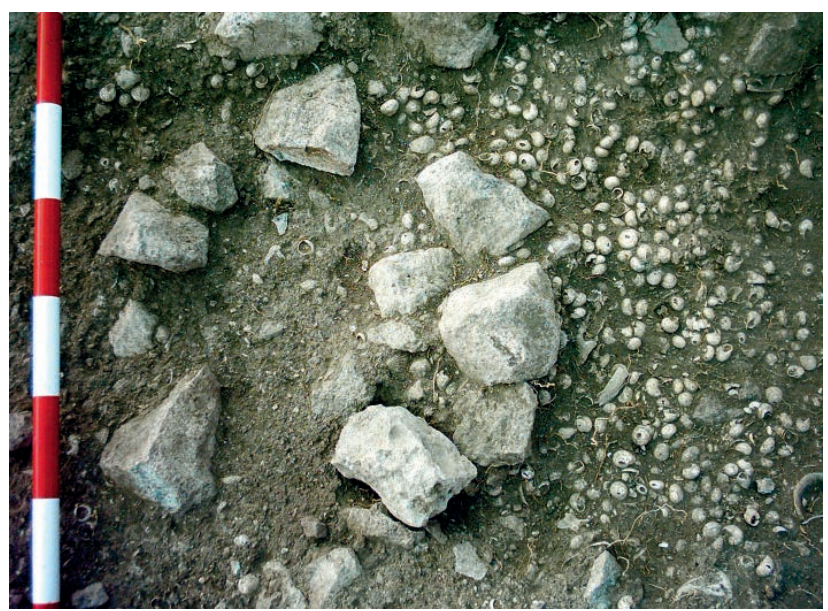

Estructura circular excavada durante la campaña de 2003 rodeada de un conchero formado por las diferentes especies animales consumidas, entre ellas caracoles, mejillones, lapas, etc. 
En la campaña de 2004 se incorporó al proyecto de investigación Chafarinas un equipo de la Universidad deValladolid. Se desarrolló entonces la tercera campaña arqueológica en el yacimiento neolítico con un mayor despliegue de personal. Se realizó una excavación en área de 9 x 5 m. en un amplio sector del yacimiento, inmediatamente al sur de la zona donde se había intervenido en las campañas anteriores. Esta actuación determinó el alto proceso erosivo que había afectado al yacimiento debido a la acusada inclinación de la superficie de la isla, sin embargo, por otro lado, se comprobó que, en los sector es de mayor evidencia arqueológica y menos erosionados se hallaba una amplia variedad de estructuras de hábitat de un extraordinario valor e interés. Pudieron documentarse entonces hoyos, hogares definidos por pequeñas estr ucturas circulares o zonas de comb ustión de distinta complejidad situadas tanto en la perferia como en el interior de la cabaña excarada en la roca, estructura más compleja e interesante respecto a las demás descubierta durante la intervención. Para entonces, los resultados de esta campaña de excavación en Zafrín habían desbordado las expectaivas previas que se tenían de la potencialidad del sitio. Las intervenciones anteriores evidenciaron que se trataba de un lugar de hábitat del Neolítico antiguo cardial, donde se conser vaban estructuras domésticas y que había deparado sorprendente riqueza de materiales arqueológicos. En 2004, la excavación en área permitió documentar el perímetro completo de una interesantísima estructura de hábitat que resultaba excepcional dentro del panorama del Neolítico Antiguo norteafricano.

En el año 2005 se produce la cuarta campaña de excavación en Zafrín para intervenir en distintos sector es situados en los extr emos norte y sur del ár ea delimitada por la prospección de 2000. La excavación en esta zona proporcionó dos buenos ejemplos de un contexto arqueológ ico primario aunque notablemente alterado por la erosión. Durante esta campaña se realizaron trabajos complementarios en diferentes zonas del archipiélago, que consistieron en la prospección intensiva de la isla del Re, el informe detallado de los bancales del brazo norte de la isla del Congreso, aterrazamientos ya documentados en el año 2000, y un inventario de abrigos y cuevas, labores destinadas a encontrar evidencias o vinculación de otros elementos al yacimiento neolítico.

En estos primeros años trabajando en el archipiélago de las Chafarinas se puso de manifiesto la riqueza histórica y arqueológica de las islas. En esos momentos fuimos conscientes de la relevancia y calidad de los hallazgos. 

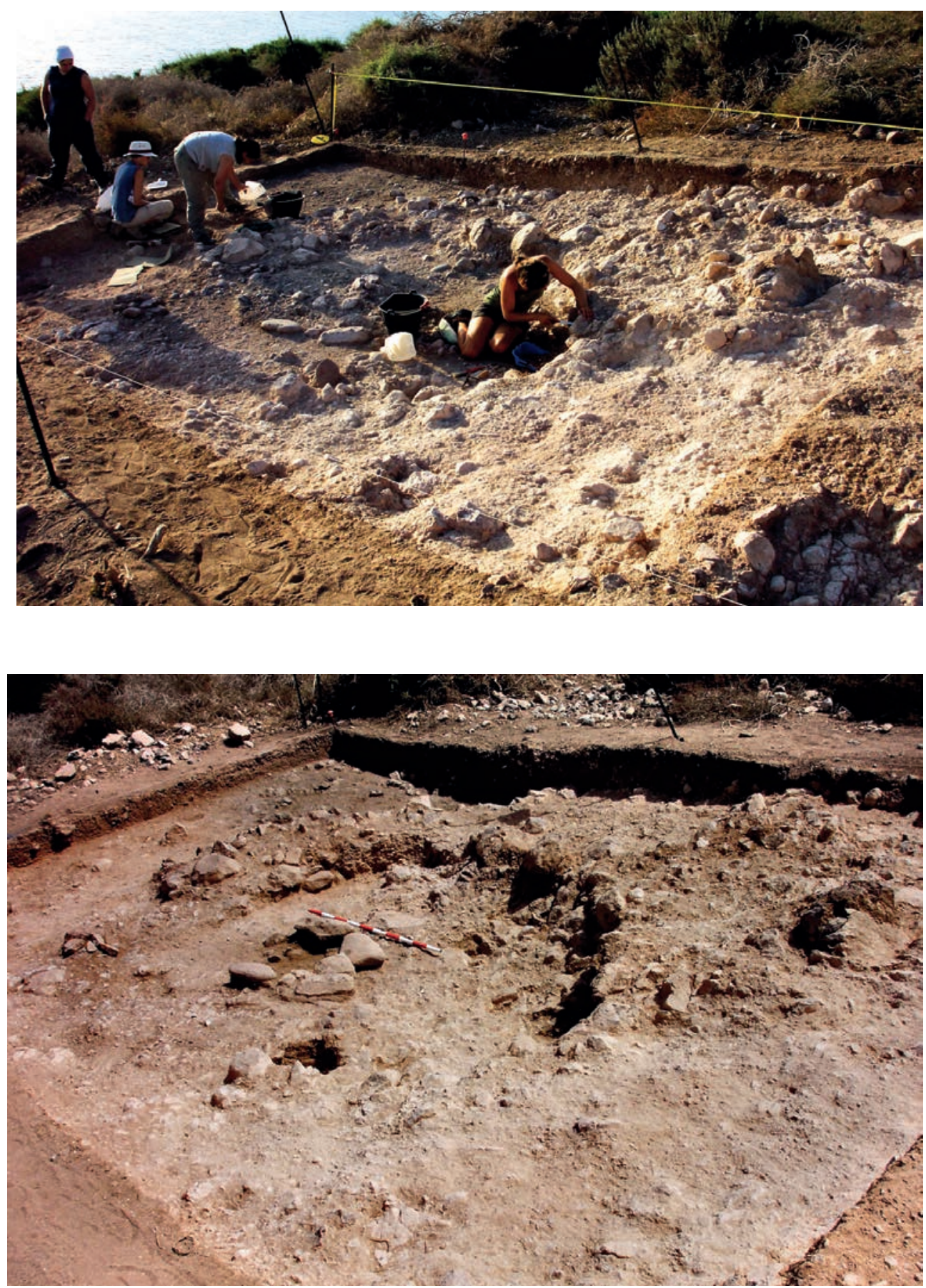

Proceso de excavación de la cabaña durante la campaña de 2004 en Zafrín. Diferentes estructuras se evidencian en su interior, postes, hogares, muretes o zonas de combustión. 


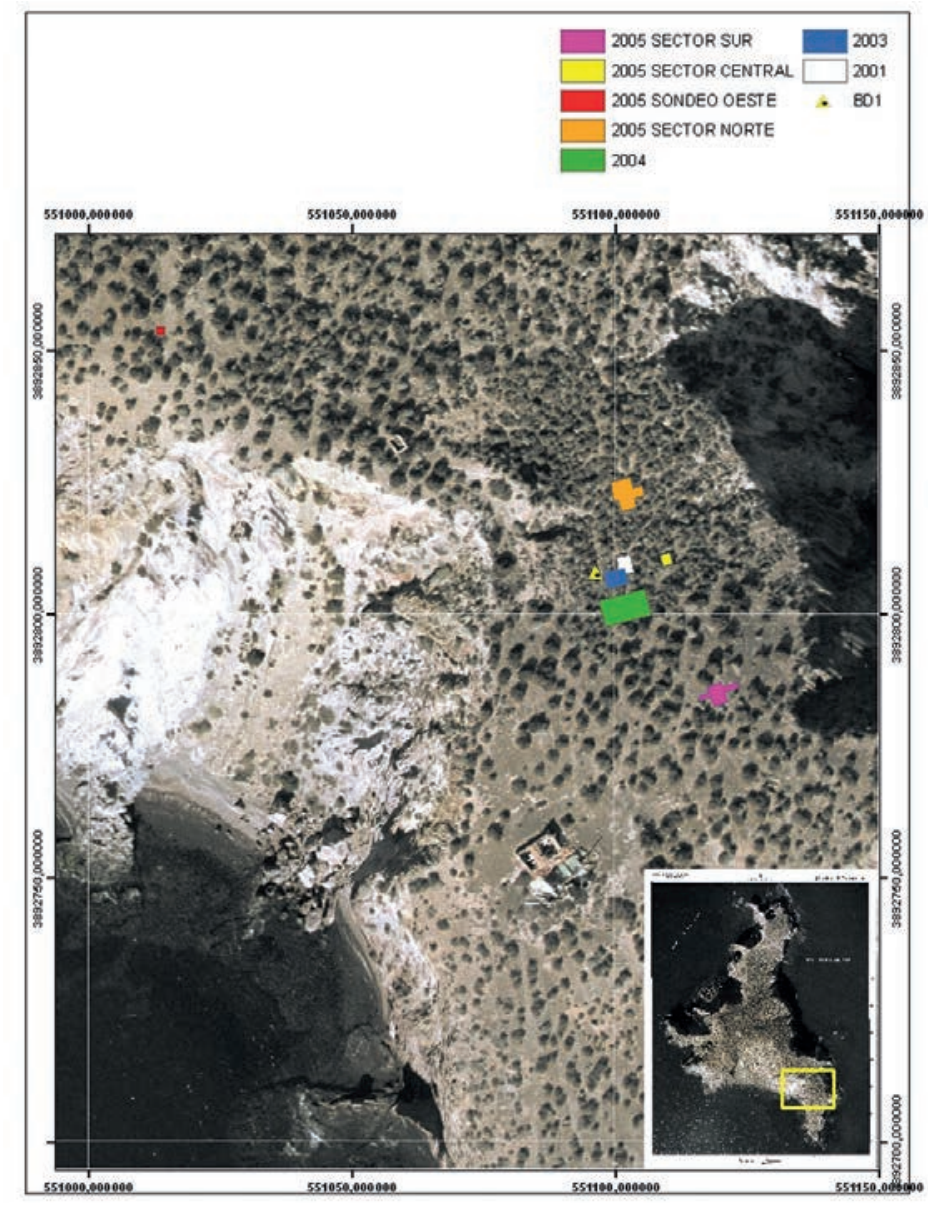

Diferentes campañas desarrolladas en el yacimiento de Zafrín

Con las ampliaciones de estas campañas se pudo profundizar en los aspectos socioeconómicos de las gentes que habitaron estas islas durante el Neolítico. Podemos asegurar sin mucho reparo, que las ocupaciones más antiguas tuvieron lugar a principios de la segunda mitad del Quinto milenio antes de Cr isto, muy posiblemente por grupos humanos pertenecientes a los hor izontes cardiales que predominaban por entonces en el Mediteráneo occidental europeo. Todas las teorías sobre su expansión explican el Neolítico Cardial como la r espuesta a una influencia externa, ya sea ésta por aportación de contingentes, a través de la navegación costera o por fenómenos de aculturación sin traslado de gupos humanos. De cualquier forma y paulatinamente, el neolítico se extiende por los nuevos territo- 
rios por los que se desplazaban. Dentro de este esquema Chafarinas sería un punto extremo de esa expansión por la costa del Rif. Así debe ser afirmado que, a día de hoy, no se conocen más allá de este punto geog ráfico costero ningún otro yacimiento neolítico con cerámica cardial. Solo en el inter ior del continente, a una treintena de kilómetros al sur, se ha exca vado recientemente el abr igo de Hassi Ouenzga, que parece tener una fase cardial. El grupo argelino tiene como cerámica representativa la de superficies lisas o con incisiones.

Fueron varios los aspectos en los que continuamos trabajando en el Pr oyecto Chafarinas, por ello, en cada campaña nos interesaba ir profundizando en diversas particularidades. Primero las vinculadas a la temporalidad de la estancia de estas gentes en el lugar. Analizar las bases económicas o de explotación del medio, en sus diversas formas de interacción: agrícolas, ganaderas, pesqueras y recolectoras tanto de vegetales como de animales (nos $r$ eferimos a caracoles y lapas de mar), o de intercambios (comercio incipiente). Otros factores son los supeditados al entorno geográfico, que es uno de los mæores retos interpretativos del yacimiento, por cuanto ha de in vestigar el grado de conexión de la actual costa con el archipiélago y su posible relación entre ocupación-desocupación del territorio insular. Trabajamos en las líneas señaladas por el equipo de geólogosA fecha de hoy podemos intuir la solución de algunos de estos retos mientras que otros pueden considerarse claramente probados. A la luz de los hallazgos está demostrado que en Zafrín se practicaba una economía mixta muy completa que comprendía la explotación tanto de r ecursos silvestres como domésticos. Así, los numerosos molinos de mano que se han extraído del gcimiento, la acumulación de semillas, las grandes vasijas cerámicas y las estructuras-cubetas excavadas, parecen indicar una economía de producción. Los restos de peces, focas, caracoles, indican una actividad r ecolectora más típica de economías pr eneolíticas, o quizás son gentes con un modo de vida or ientado principalmente a la explotación del medio marino, complementado con cierta actividad ganadera y agrícola. En lo que se refiere a la domesticación de animales, la ganadería, hemos identificado especies claramente apor tadas por el hombre, en concreto un tipo de ovicaprino de aspecto grácil. Sin duda los taxones presentes de especies silvestres o no domésticas son más numer osos. Desde aves de varios tipos hasta la presencia ya documentada de focas (taxones mandibulares y algún hueso largo), con lo que hemos demostrado que esta especie ya era objeto de caza en las islas en estos estadios de la prehistoria. 


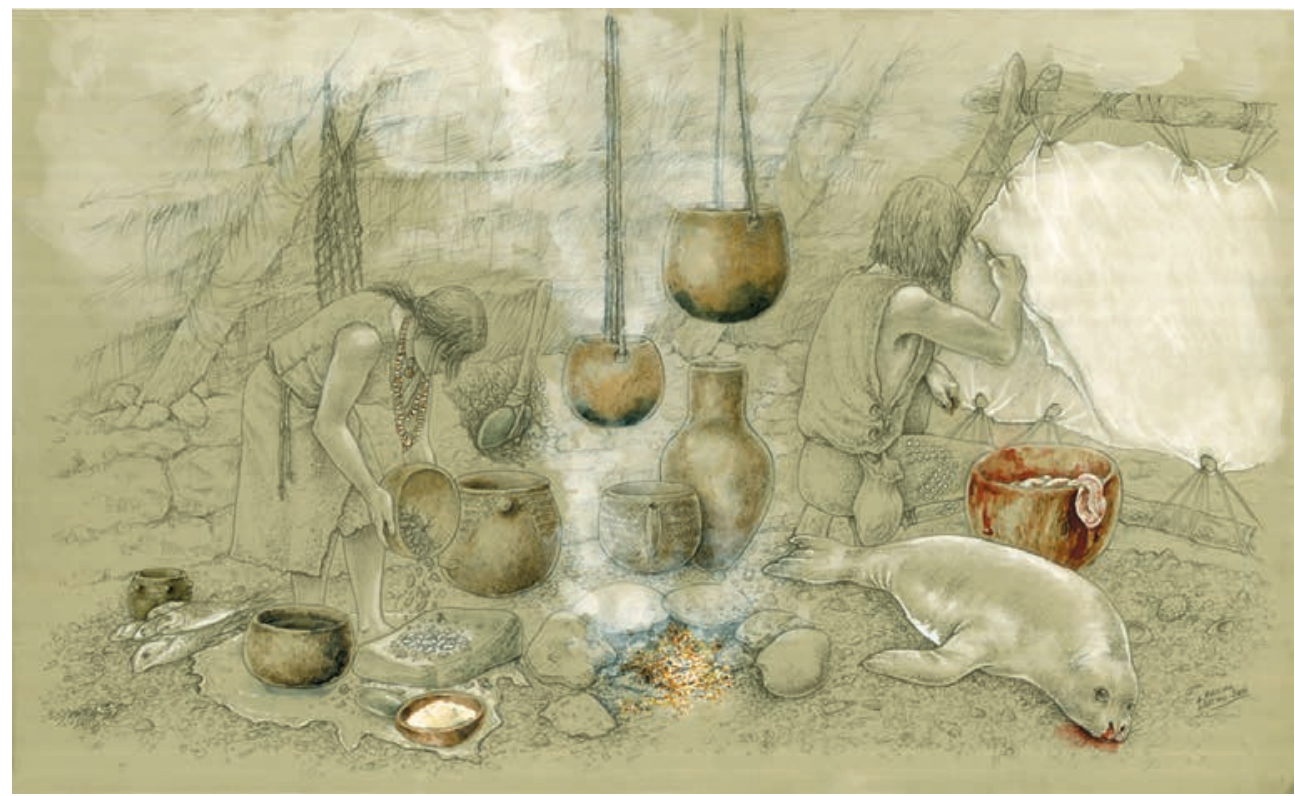

Economía de los pobladores de Zafrín basada en la recolección de cereales y explotación de recursos marinos y terrestres que les aportaban las islas. Dibujo: Luis Pascual (Aratikos)

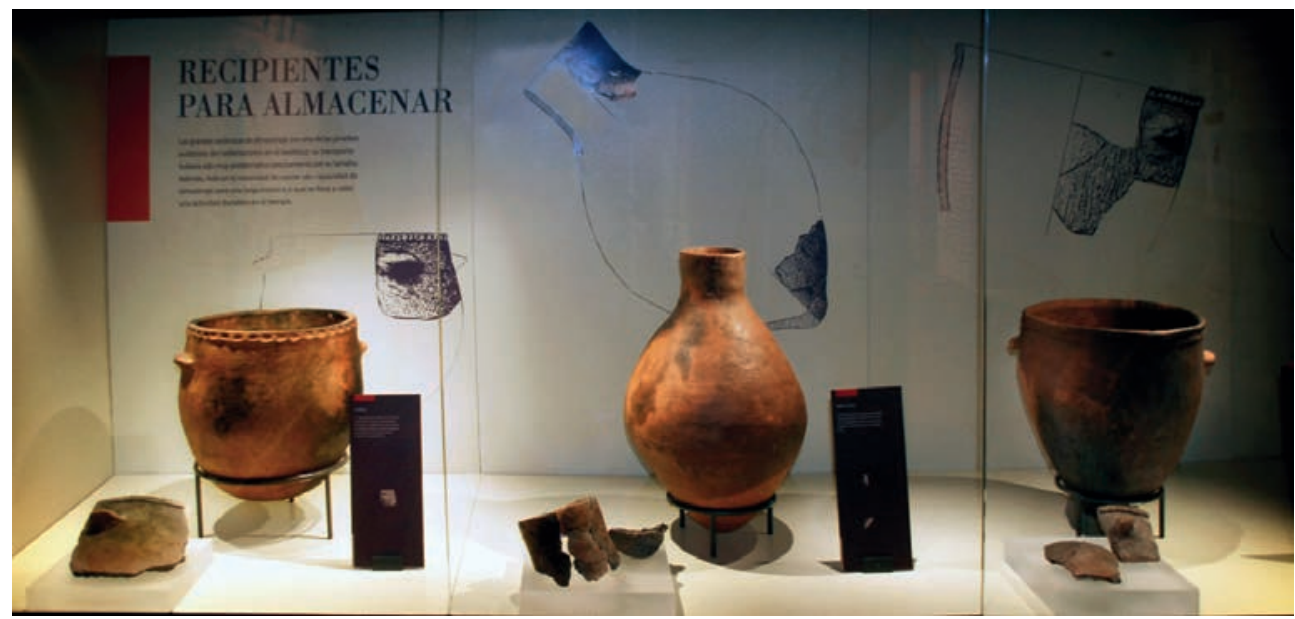

Tipología de las cerámicas de gran tamaño excavadas en el yacimiento de Zafrín. Fotografía: Rafael Hernández.

El número de hallazgos cerámicos en la I Campaña superó finalmente los mil fragmentos. Se inventarió por cuadrículas según tipo, forma, técnica decorativa, acabados y categoría de desgrasante. Cerámicas lisas y decoradas en las que 
los elementos de prensión principales son los mamelones y algún fragmento con orificios de sustentación. Las formas responden a diferentes tipologías: grandes vasijas de almacenamiento, a pequeños cuencos con decoración cardial.

Buena parte de la manufactura cerámica está hecha a mano con la técnica de rollos. Ésta consiste en un procedimiento bastante simple que es la superposición de tiras de arcilla, denominadas rollos o churros, para ir ampliando la pieza verticalmente desde una base que consiste en una planc ha de cerámica o la unión de diferentes tiras de barro. Estos rollos serán de diferente grosor, dependiendo de la pieza que quiera elaborar se. Hay casos en que ni siquiera es tra tada la superficie externa, pudiendo ser observado perfectamente la superposición de estos rollos.

Otro elemento del registro arqueológico es la industria lítica. El sílex, del que una parte procede de materias primas ajenas al archipiélago, indicando que además de la cantera de la isla del Reg se buscaron otros lugares donde extraer el preciado material, la estructura y textura de las piezas así par ece indicarlo. Los molinos de tipología barquifor me y sus cor respondientes manos de difer entes tamaños. Una de las citadas manos puede ser una afiladora o pulidoraLa materia prima es principalmente la roca volcánica más común, la andesita, de la que se fabrica una interesante pieza, un lámina de $127 \mathrm{~mm}$., posiblemente un cuchillo. También señalar la existencia de fragmentos de cáscara de hueo de avestruz, sin decorar, cuya función siempre se ha relacionado con el transporte de líquidos.

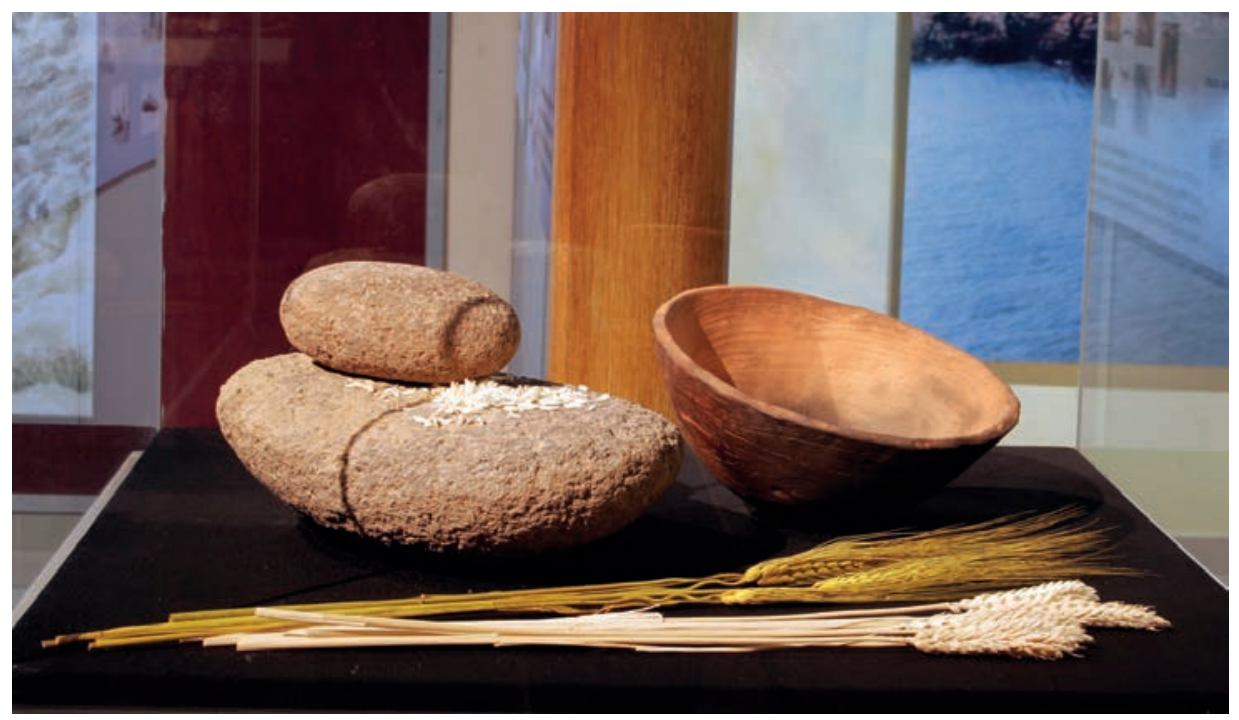

Molino de piedra del yacimiento de Zafrín. Fotografía: Rafael Hernández. 
Hoy podemos disfrutar en los nuevos museos de las Peñuelas, en Melilla, de todos estos materiales recuperados durante los diez años de investigación en las islas Chafarinas. Una sala específica recrea la vieja cabaña neolítica y podemos contemplar todos los útiles y objetos que fuer on elaborados por estas gentes . Destacaríamos de este museo la escenografía o recreación de la cabaña excavada en la Campaña de 2004 y que ha sido ampliamente dada a conocer (Rojo et al., 2010). Una estructura que es un resumen muy ilustrativo de toda la información que nos han deparado las diversas intervenciones arqueológicas: la planta y alzado de la cabaña, la distribución del espacio según actividades económicas tales como cocina, tallado del sílex, preparación de granos a través de la molienda, cerámicas de cocina, o el hacha que olvidaron en un hueco al fondo de la cabaña y que hallamos in situ. También los restos de la comida ya consumida: caracoles, lapas, vértebras de pez, huesos de ovejas y foca, y el propio hogar constituyen la recreación de una forma de vida bien definida.
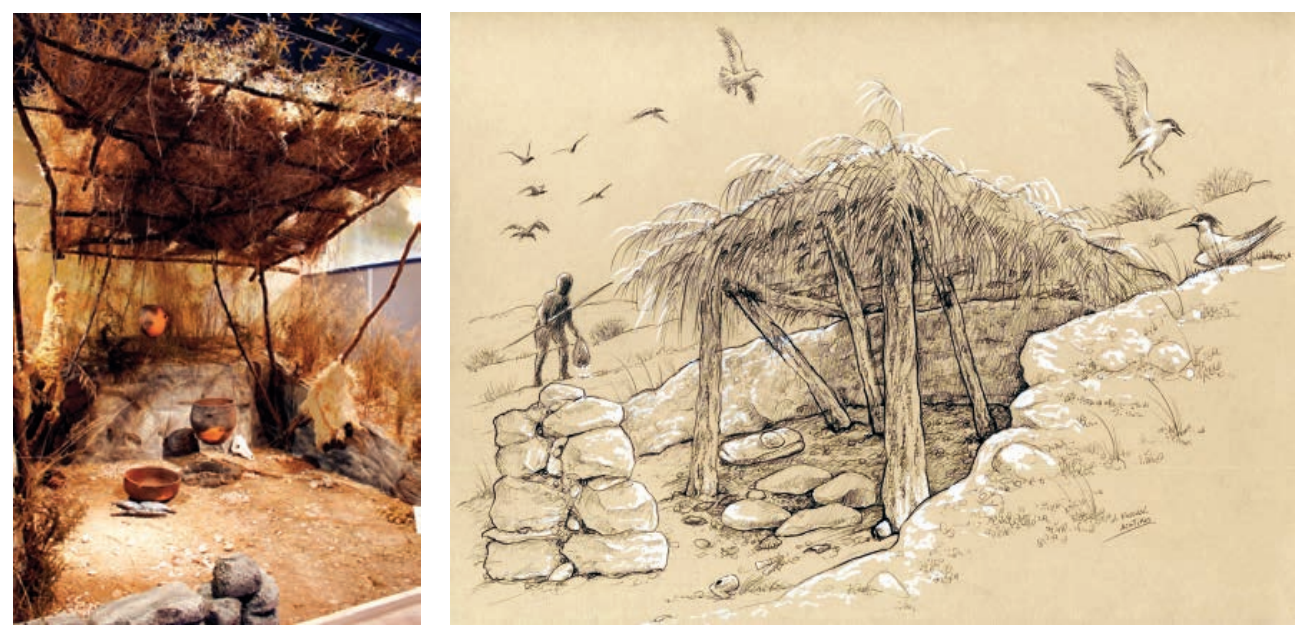

Escenificación de la cabaña excavada en el yacimiento de Zafrín, Museo de Arqueología e Historia de Melilla, a la izquierda. Idealización basada en las estructuras excavadas. Dibujo: Luis Pascual (Aratikos)

Las distintas actividades que el hombre lleva a cabo en su cabaña dejan una huella, un mapa de distribución de basuras. Alrededor del fuego se pueden inentariar cientos de caracoles terrestres junto a las lapas, al otro lado se pueden ver los molinos de mano que sirven para moler el grano de cereal o para conseguir polvo de color para recubrir superficies o embadurnar el propio cuerpo del hombre. 


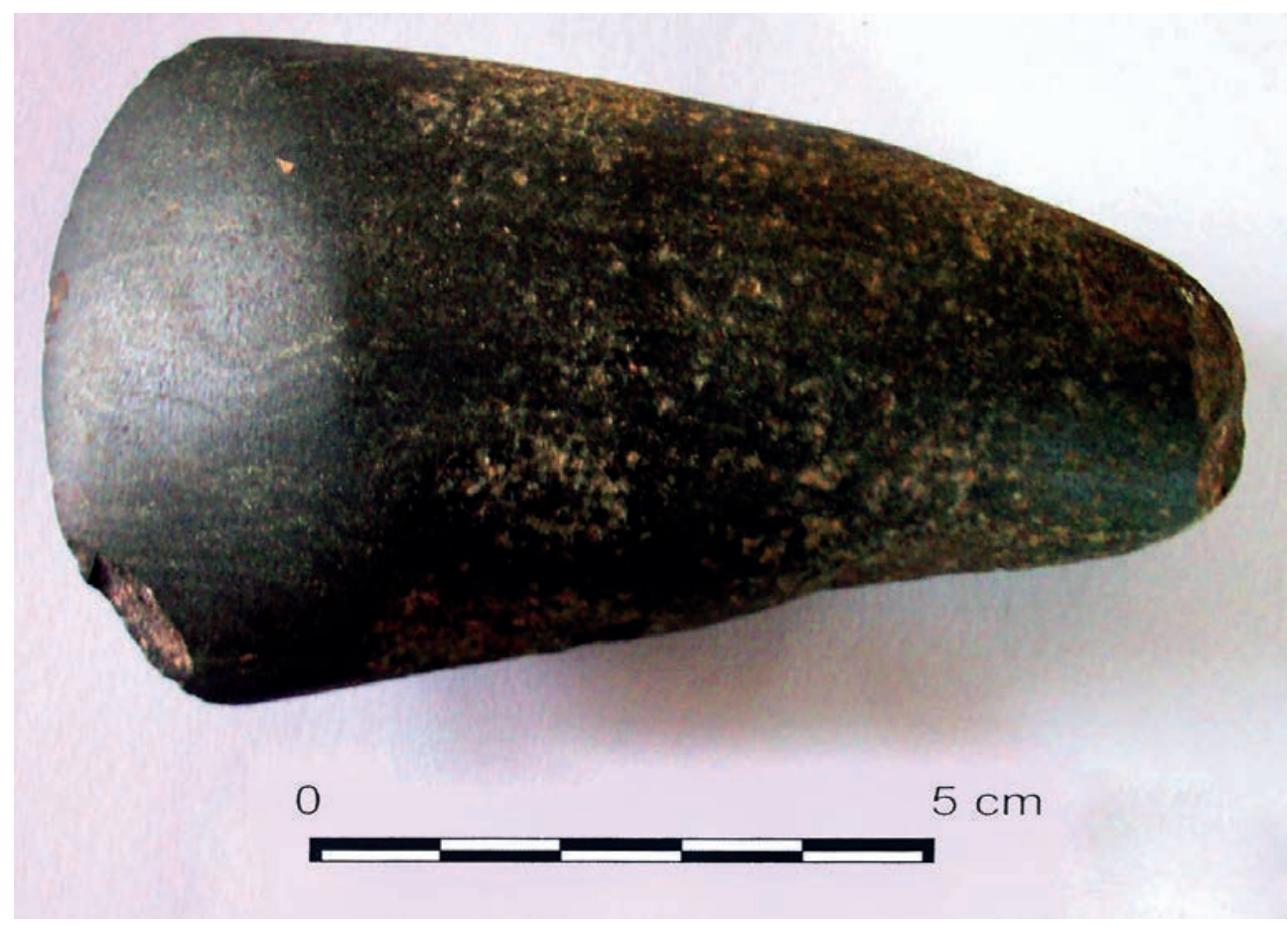

Hacha pulimentada hallada en una pequeña oquedad en el interior de la cabaña excavada en la roca en el yacimiento de Zafrín.

Es muy probable que en las otras dos islas que for man el archipiélago, Isabel II y del Rey, existiera ocupación en el neolítico, numerosos restos de sílex repartidos en toda la superficie hace sospechar que así fue. Sin embargo, la isla de Isabel II ha sufrido una intensa ocupación desde 1848 que ha hecho desaparecer prácticamente toda huella de nuestr os antepasados. Igualmente, la del Rey ha soportado un proceso erosivo tan agresivo que no ha permitido la recuperación de los restos arqueológ icos que hayan podido existir, a pesar de que en diferentes campañas de prospección se han recuperado numerosos restos líticos así como las afloraciones de sílex ya comentados.

Actualmente Zafrín sigue siendo un yacimiento atípico por su ubicación, que ha permitido una conservación más que aceptable. Las enseñanzas que se han podido extraer nos pemite conocer mucho mejor las formas de vida en elV milenio antes de Cristo en esta área del Mediterráneo. 


\section{BIBLIOGRAFÍA}

ÁLVAREZ-FERNÁNDEZ, E. (2010): "Percebes y bellotas de mar. los cirrípedos del yacimiento neolítico de el Zafrín (isla del Congeso, islas Chafarinas)”. En Rojo Guerra, M., et al. 2010: Zafrín: Un asentamiento del neolítico antiguo en las islas Chafarinas (Norte de África, España). Studia Archaeologica. Universidad de Valladolid; pp 213-223.

ÁLVAREZ-FERNÁNDEZ, E., Valledor de Lozoya,A.;Aparicio Alonso, MaaT. (2010): "Los moluscos terrestres del yacimiento neolítico de El Zafrín (isla del Congreso, islas Chafarinas)”. En ROJO GUERRA, M., et al. 2010: Zafrín: Un asentamiento del neolítico antiguo en las islas Chafarinas (Norte de África, España). Studia Archaeologica. Universidad de Valladolid; pp 223-231.

BARRERA, J. L. y PINEDA, A. (2007): "Las islas Chafarinas. La geología de un archipiélago deseado por todos”. En: Tierra y Tecnología, 30; pp.13 - 30.

BELLVER GARRIDO, J. A. (2010): "Fauna arqueológica en las Islas Chaf arinas. Zafrin una estación neolítica al air e libre”. En: AA.VV. Zafrin, un asentamiento del neolítico antiguo en las islas Chafarinas. Valladolid: Universidad; p. 177-192.

BELLVER GARRIDO, J. A. y BRAVO NIETO, A. (2002). “Descubierto un poblado neolítico delV milenio A.C. en las islas Chafarinas”. Parques Nacionales, Ambienta; p. 12-14.

BELLVER GARRIDO, J.A. y BRAVO NIETO, A (2003). “Una estación neolítica al aire libre en las islas Chafarinas. Primera datación radiocarbónica”. Akros. $\mathrm{N}^{\circ}$ 2; p. 79-86.

BRAVO NIETO, A. y BELLVER GARRIDO, J. (2004): Prehistoria del Rif Oriental en la obra de Carlos Posac Mon. Melilla: Instituto de Cultura Mediter ránea; pp $181-195$.

BUXÓ, R. (1997): La arqueología de las plantas. Barcelona: Crítica.

EXPÓSITO, I. y BURJACHS, F. F. (2003): “Análisis palinológico del yacimiento arqueológico de El Zafr in (isla del Congreso, islas Chafarinas, Melilla)”. Informe inédito. Arqueoline, Tarragona.

GIBAJA GAO, F. (2010): "La función del utillaje lítico tallado del asentamiento neolítico de Zafrín (islas Chafarinas)”. En: Rojo Guerra, M., et al. 2010: Zafrín: Un asentamiento del neolítico antiguo en las islas Chaf arinas (Norte de África, España). Studia Archaeologica. Universidad de Valladolid. 
LÓPEZ SAIZ, J. A., LÓPEZ GARCÍA, P., LÓPEZ MERINO, L. (2010): "Paleoambiente de las islas Chafarinas durante el neolítico antiguo:análisis polínicos en el yacimiento arqueológico de Zafrín (isla del Congreso, Melilla)”. En: ROJO GUERRA, M., et al. 2010: Zafrín: Un asentamiento del neolítico antiguo en las islas Chaf arinas (Norte de África, España). Studia Archaeologica. Universidad de Valladolid; pp 165-177.

PINEDA VELASCO, A. (2003): "Estudio geológico”. En BELLVER, J., y BRAVO, A.: El yacimiento de Zafrín en las islas Chaf arinas, II Campaña. Melilla: Instituto de Cultura Mediterránea.

POSAC, C. (1956): "Prehistoria de las islas Chafrinas". Tamuda, año IV, Semestre II. Tetuán: Imprenta Cremades.

ROJO, M.; BELLVER, J. A.; BRAVO, A.; GARRIDO, R.; GARCÍA, I. y GÁMEZ, S. (2004). "El yacimiento de Zafrín en las islas Chafarinas (Norte de África, España): un nuevo asentamiento del neolítico cardial”.En: Do Epipaleolitico ao Calcolítico na Península Ibérica. IV Congreso de arqueología peninsular en Portugal en 2004; p. 127-134.

ROJO, M., BELLVER, J.A., BRAVO, A., GARRIDO, R., GARCÍA, I. y GÁMEZ, S. (2005). "El yacimiento neolítico de Zafrín en las islas Chafrinas (Norte de África, España): avance de los resultados de la campaña de excaración 2004”. Akros. $\mathrm{n}^{\circ}$ 4; p. $101-106$.

ROJO, M., BELLVER GARRIDO, J. A., BRAVO NIETO, A, GARRIDO, R., GARCÍA, I. y GÁMEZ, S. (2007), Una mirada al pasado: Prehistoria de las islas Chafarinas. Fundación GASELEC- Universidad de Valladolid.

ROJO GUERRA, M., et al. (2010):Zafrín: un asentamiento del neolítico antiguo en las islas Chafarinas (Norte de África, España). Studia Archaeologica. Universidad de Valladolid. 